\title{
Selective Targeting of Cancer Cells by Copper lonophores: An Overview
}

\author{
Valentina Oliveri * \\ Dipartimento di Scienze Chimiche, Università Degli Studi di Catania, Catania, Italy
}

Conventional cancer therapies suffer from severe off-target effects because most of them target critical facets of cells that are generally shared by all rapidly proliferating cells. The development of new therapeutic agents should aim to increase selectivity and therefore reduce side effects. In addition, these agents should overcome cancer cell resistance and target cancer stem cells. Some copper ionophores have shown promise in this direction thanks to an intrinsic selectivity in preferentially inducing cuproptosis of cancer cells compared to normal cells. Here, $\mathrm{Cu}$ ionophores are discussed with a focus on selectivity towards cancer cells and on the mechanisms responsible for this selectivity. The proposed strategies, to further improve the targeting of cancer cells by copper ionophores, are also reported.

\section{OPEN ACCESS}

Edited by: Chiara Nardon,

University of Verona, Italy

Reviewed by:

Qingping Dou,

Wayne State University, United States

Xin Chen,

Guangzhou Medical University, China Fabio Arnesano,

University of Bari Aldo Moro, Italy

*Correspondence:

Valentina Oliver valentina.oliveri@unict.it

Specialty section:

This article was submitted to

Molecular Diagnostics and

Therapeutics,

a section of the journal

Frontiers in Molecular Biosciences

Received: 22 December 2021

Accepted: 09 February 2022

Published: 04 March 2022

Citation:

Oliveri V (2022) Selective Targeting of Cancer Cells by Copper lonophores:

An Overview.

Front. Mol. Biosci. 9:841814.

doi: 10.3389/fmolb.2022.841814
Keywords: copper ionophores, cuproptosis, cuproplasia, ROS, prodrug, chemotherapeutics, anticancer

\section{INTRODUCTION}

Copper $(\mathrm{Cu})$ is an essential mineral nutrient for all living organisms as it is fundamental in a huge number of biological processes including mitochondrial respiration, iron uptake, antioxidant/ detoxification processes (Ruiz et al., 2021). Recently, the role of $\mathrm{Cu}$ has also emerged in signaling as a factor that regulates or triggers several biological pathways upon an external stimulus (Li, 2020; Michniewicz et al., 2021). Nevertheless, many connections have been observed between disease statuses and $\mathrm{Cu}$. As for cancer, several studies have reported higher levels of $\mathrm{Cu}$ in a variety of malignancies compared to normal tissues. $\mathrm{Cu}$ accumulation has been associated with enhanced proliferation and growth, angiogenesis, and metastasis. It is evident that the dyshomeostasis of $\mathrm{Cu}$ plays a prominent role in cancer, although researchers debate if it is a cause or a consequence of tumorigenesis. In particular, $\mathrm{Cu}$ levels of both serum and tumor tissues have been found significantly altered in patients suffering from different cancers such as breast, thyroid, cervical, ovarian, lung, pancreatic, prostate, gastric, oral, bladder cancers (Basu et al., 2013; Ding et al., 2015; Pavithra et al., 2015; Baltaci et al., 2017; Stepien et al., 2017; Zhang and Yang, 2018; Chen et al., 2019; Aubert et al., 2020; Saleh et al., 2020; Michniewicz et al., 2021). There is some evidence that $\mathrm{Cu}$ could have a role in the etiology, severity, and progression of cancer disease (Ishida et al., 2013; Shanbhag et al., 2021). This hypothesis is, for example, supported by the enhanced incidence of hepatocarcinoma in Wilson's disease patients, the correlation between the stage and Cu levels in colorectal and breast cancer, the link between $\mathrm{Cu}$ exposure, pancreatic and prostate cancer (Gupta et al., 1993; Sharma et al., 1994; Ishida et al., 2013; Gunjan et al., 2017; Vella et al., 2017). Moreover, some mechanisms, involved in $\mathrm{Cu}$-dependent growth and progression of tumors, have been recently found and summarized elsewhere (Lelièvre et al., 2020; Ge et al., 2021; Ruiz et al., 2021). Cu is also able to promote angiogenesis that is essential for tumor progression and metastasis. In particular, mounting evidence suggests that $\mathrm{Cu}$ can activate many angiogenic factors, such as angiogenin (hAng), vascular endothelial growth factor (VEGF), fibroblast growth factor 1 (FGF1), and interleukin 1 (IL-1), etc. Moreover, Cu can stabilize nuclear hypoxia-inducible factor-1 (HIF-1), 

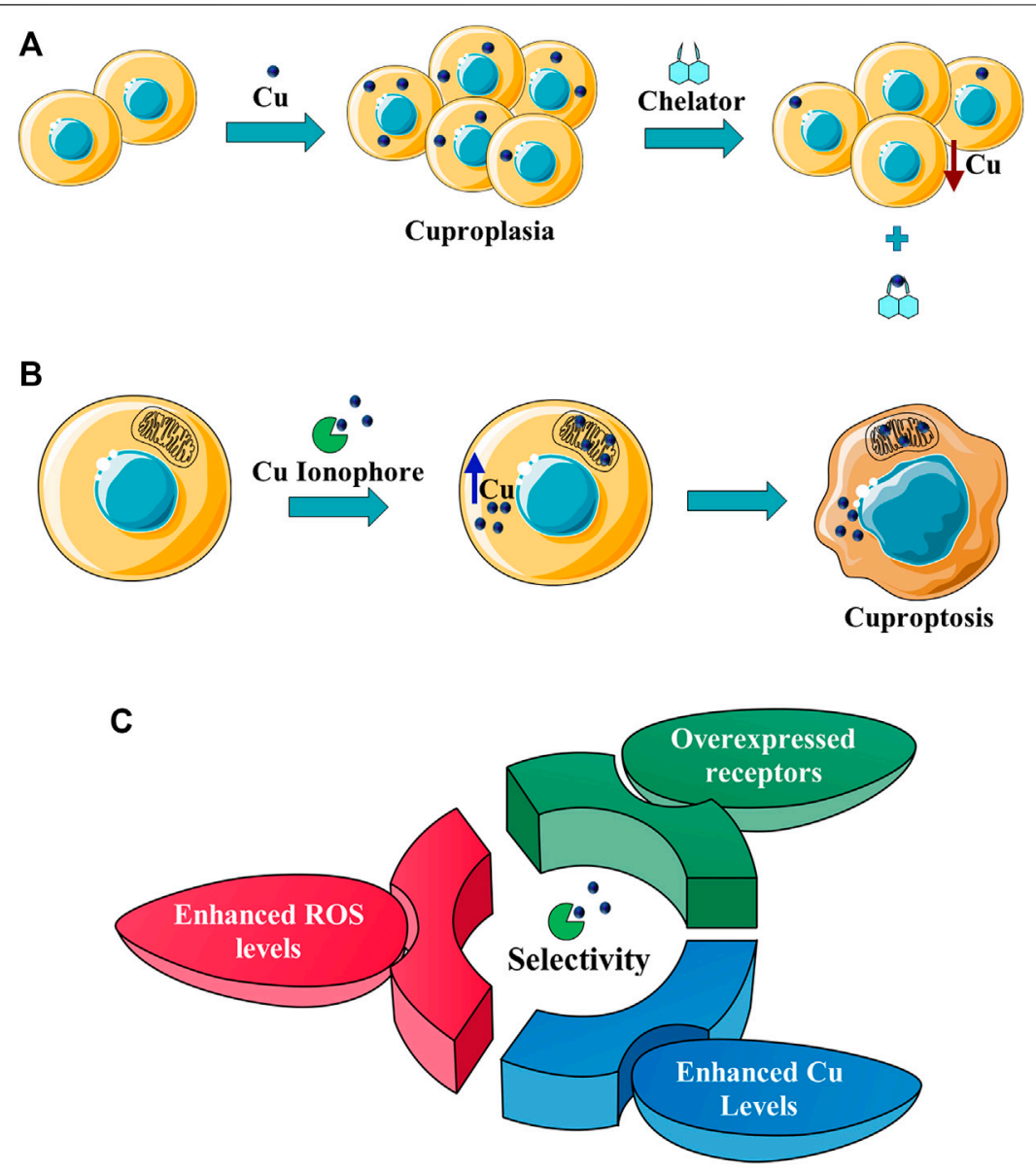

FIGURE 1 | (A) Cu chelators inhibit cuproplasia (a Cu-dependent cellular proliferation), decreasing the intracellular Cu concentration; (B) Cu ionophores induce cuproptosis, increasing the intracellular (in particular in mitochondria) Cu levels and leading to cell death; (C) the intrinsic selectivity of Cu ionophores results from different factors: the increased Cu levels in cancer tissues, the enhanced levels of ROS species that make cancer cells more susceptible to a further increase of oxidative stress, the targeting of receptors overexpressed in cancer cells.

therefore further augmenting the expression of the proangiogenic factors (Shao et al., 2019; Lelièvre et al., 2020; Li, 2020). Therefore, $\mathrm{Cu}$ alone or bound to ligands promotes angiogenesis in different in vitro and animal models whereas $\mathrm{Cu}$ chelation suppresses this process.

Since the key role exerted by $\mathrm{Cu}$ in the genesis, severity, and progression of cancer, it could be a vulnerable point to target for arresting cancer development (Shanbhag et al., 2021). Conventional cancer therapies suffer from severe off-target effects because most of them target critical facets of cells that are generally shared by all rapidly proliferating cells. Future goals of new therapeutics should aim to increase the selectivity reducing side-effects, overcome cell resistance, and finally, target cancer stem cells. Some metal-binding compounds have shown promise in this direction. These systems are finely summarized in a recent paper (Steinbrueck et al., 2020).

Here, $\mathrm{Cu}$ ionophores are discussed with a focus on the selectivity towards cancer cells, the mechanisms responsible for the selectivity (Figure 1), and the strategies proposed to further increase the targeting of cancer cells by copper ionophores.

\section{COPPER IONOPHORES}

$\mathrm{Cu}$ metal-binding compounds have a huge potential for the treatment of cancer as well discussed in the review written by Steinbrueck et al. (2020). However, this field is at an early stage of development. In particular, the lack of selectivity is one of the major challenges in this area. Therefore, new Cu-binding compounds able to target selectively cancer cells are highly sought-after. When we refer to Cu-binding compounds, different classes of $\mathrm{Cu}$ ligands are included such as $\mathrm{Cu}$ chelators and $\mathrm{Cu}$ ionophores. $\mathrm{Cu}$ ionophores differ from $\mathrm{Cu}$ chelators for their mechanism of action as reported elsewhere (Oliveri, 2020; Ge et al., 2021). In particular, $\mathrm{Cu}$ chelators inhibit cuproplasia, a $\mathrm{Cu}-$ dependent cellular proliferation, whereas $\mathrm{Cu}$ ionophores induce cuproptosis (Figure 1). This last term defines Cu-dependent cytotoxicity (with a unique mechanism) leading to cell death (Tsvetkov et al., 2019). 
TABLE 1 | The abbreviations and the structures of $\mathrm{Cu}$ ionophores mentioned in the paper.

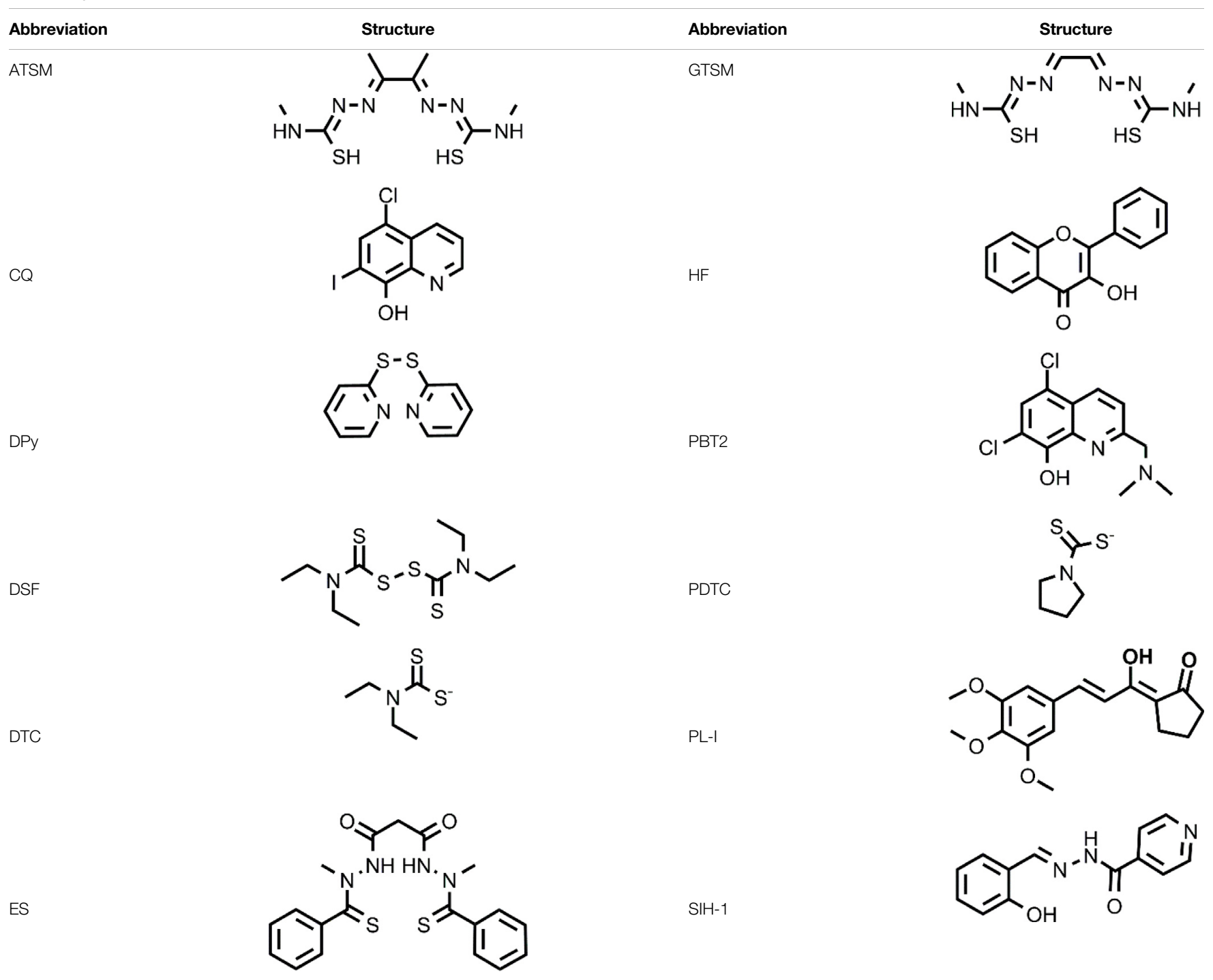

Many different classes of $\mathrm{Cu}$ ionophores have been pursued as anticancer agents to promote cuproptosis, including dithiocarbamates, bis(thiosemicarbazone) ligands, 8hydroxyquinolines (HQs), flavones, etc (Denoyer et al., 2015; Hunsaker and Franz, 2019; Lelièvre et al., 2020; Li, 2020; Ge et al., 2021). The structure of the $\mathrm{Cu}$ ionophores mentioned in this paper is reported in Table $\mathbf{1}$. The most known and studied dithiocarbamates as anticancer ionophores are pyrrolidine dithiocarbamate and diethyldithiocarbamate (DTC), which is the active form of the better-known disulfiram (DSF). DSF is an FDA-approved aldehyde dehydrogenase inhibitor for the treatment of alcoholism, and it has been effectively used for over 60 years. DSF, however, possesses other biological activities and there is been growing attention in repurposing DSF as an anticancer agent (Ekinci et al., 2019; Kannappan et al., 2021). This interest arises from the low cost, high availability, safety profile, and anticancer activity of DSF. In the last years, DSF has demonstrated to act as an anticancer agent against a variety of cancer cell lines (Allensworth et al., 2015; Hassani et al., 2018; Park et al., 2018; Li et al., 2020b). Moreover, numerous studies have shown that the administration of DSF with $\mathrm{Cu}$ significantly increases its anticancer action because the active form of DSF is the Cu complex of DTC. The toxicity of DSF seems to be strictly related to the intracellular accumulation of $\mathrm{Cu}$, promoted by DSF (Cen et al., 2004). The mixture Cu-DSF has been tested as an adjuvant in combination with known chemotherapeutic drugs such as cisplatin, temozolomide, gemcitabine, doxorubicin, etc (Li H. et al., 2020). Mounting evidence has demonstrated that $\mathrm{Cu}$ DSF can have several targets including ROS levels, the ubiquitinproteasome system (UPS), nuclear factor-kappa B (NF- $\kappa \mathrm{B}$ ), NPL4 (Chen et al., 2006; Skrott et al., 2017; Oliveri, 2020; Kannappan et al., 2021). Despite the excellent results of DSF in vitro and in vivo, clinical studies of DSF in patients with cancer were not successful. This disappointing outcome could be related to the rapid degradation of DSF and its active metabolite or a different route of administration of DSF and $\mathrm{Cu}$. The chemistry, 
pharmacokinetics, pharmacodynamics of DSF are comprehensively summarized by Kannappan et al. (2021). So, here, only some aspects related to selectivity, are discussed. CuDSF has shown to preferentially target cancer cells compared to normal cells and can also target cancer stem cells (CSC) (Yip et al., 2011; Hothi et al., 2012; Liu et al., 2016; Xu et al., 2017; Sun et al., 2020; Serra Id et al., 2021). Just to give a few examples, $\mathrm{Cu}-$ DSF was strongly cytotoxic to leukemia stem-like cells in a dosedependent manner, while it did not affect normal hematopoietic progenitor cells (Xu et al., 2017). This facet may be correlated to the ability of cancer cells to accumulate $\mathrm{Cu}$ but also the oxidative susceptibility of cancer cells. Indeed, the evaluation of ROS levels in leukemia stem-like cells highlighted that the administration of $\mathrm{Cu}$-DSF led to a remarkable intracellular increase of ROS and the triggered apoptosis could be reversed by the antioxidant $\mathrm{N}$-acetylcysteine (NAC). The involvement of ROS has also been implicated in the toxic selectivity shown by Cu-DSF versus malignant prostate cancer cells compared to healthy cells (Safi et al., 2014). In this study, a significant increase of intracellular ROS was detected upon the treatment with Cu-DSF and further proof of the ROS-mediated action of Cu-DSF was observed when the administration of free-radical scavengers suppressed the apoptosis induced by Cu-DSF cotreatment (Safi et al., 2014). Elevated ROS levels are a hallmark of human prostate cancer and different studies have demonstrated that oxidative stress plays a role in the progression of prostate cancer (Kumar et al., 2008; Udensi and Tchounwou, 2016). Another interesting study supports the hypothesis that the selectivity shown by DSF arises from differences in the redox biochemistry of $\mathrm{Cu}$ in cancer vs. normal cells (Falls-Hubert et al., 2020). Cu-DSF (50-150 nM DSF and $15 \mu \mathrm{M} \mathrm{CuSO}_{4}$ ) was selectively toxic to $\mathrm{H} 292$ NSCLC cells compared to normal human bronchial epithelial cells (HBEC). In this study, $\mathrm{Cu}$ uptake was determined to be higher in cancer cells than in normal cells. As a consequence, increased redox reactions of $\mathrm{Cu}$ and higher oxidative stress characterized cancer cells compared to healthy cells. Moreover, hypoxia, which is one of the hallmarks of solid tumors, can cause the accumulation of $\mathrm{Cu}$ increasing the influx and decreasing the efflux of $\mathrm{Cu}$. In turn, this aspect seems to be associated with the $\mathrm{Cu}$ metabolism as the authors observed that the overexpression of ATP7B caused a diminished accumulation of $\mathrm{Cu}$ (Falls-Hubert et al., 2020). Targeting chloride channel-3 (ClC-3), a member of the chloride channels superfamily, is another mechanism proposed to explain the selective action of Cu-DSF versus cancer cells (Xu et al., 2019). $\mathrm{Cu}-\mathrm{DSF}$ can trigger apoptosis through the activation of ClC-3 that is overexpressed in cancer cells compared to normal cells. The overexpression (induced also by the treatment with Cu-DSF) could justify the promotion of cell apoptosis of nasopharyngeal carcinoma CNE-2Z cells $\left(\mathrm{EC}_{50}=0.32 \mu \mathrm{M}\right)$ whereas Cu-DSF did not have the same effect in nasopharyngeal epithelial NP69-SV40 T cells $\left(\mathrm{EC}_{50}=1.5 \mu \mathrm{M}\right)(\mathrm{Xu}$ et al., 2019). Overall, the selectivity, shown by $\mathrm{Cu}$-DSF, may arise due to diverse factors and targets as observed for other $\mathrm{Cu}$ ionophores (Figure 1).

Bis(thiosemicarbazone) analogs are among $\mathrm{Cu}$ ionophores that have shown anticancer activity. Diacetyl-bis(N4methylthiosemicarbazone) (ATSM) and glyoxal-bis(N4methylthiosemicarbazone) (GTSM) have proven to be effective as anticancer agents. Although these compounds have a similar structure, their mechanism of action is different. SAR studies have indicated that the diimine skeleton of bis(thiosemicarbazone) must not have substituents to exert a high antiproliferative activity. This is the case of GTSM whereas ASTM presents two methyl groups on the diamine backbone that decrease the reduction capacity of Cu-ATSM (Donnelly et al., 2012). Cu-ATSM and Cu-GTSM have been investigated as anticancer agents in prostate cancer cells in vitro and in vivo (Cater et al., 2013). $\mathrm{Cu}$-GTSM $\left(\mathrm{LD}_{50}=1.5 \mu \mathrm{M}\right)$ was more effective than $\mathrm{Cu}-\mathrm{ATSM}\left(\mathrm{LD}_{50}=7 \mu \mathrm{M}\right)$ in killing cancerous prostate PC3 cells in vitro. Moreover, Cu-ATSM and Cu-GTSM were also active against human prostate hyperplastic and carcinoma cell lines with different expression patterns whereas they did not affect human primary prostate epithelial cells (PrEC). Finally, the concomitant administration of the physiological concentration of $\mathrm{Cu}(20 \mu \mathrm{M})$ to the culture medium significantly increased the activity of Cu-GTSM $\left(\mathrm{LD}_{50}=150 \mathrm{nM}\right)$. The authors elegantly demonstrated with a metal responsive element-luciferase reporter that $\mathrm{Cu}-\mathrm{GTSM}$ can use the extracellular $\mathrm{Cu}$ to increase the intracellular $\mathrm{Cu}$ level whereas Cu-ATSM cannot (Cater et al., 2013). This different behavior is certainly related to the inability of $\mathrm{Cu}-\mathrm{ATSM}$ to release $\mathrm{Cu}$ in a reducing environment while GTSM can cause the intracellular accumulation of $\mathrm{Cu}$, transporting the ion across the membrane and releasing it. Cu-GTSM was also able to suppress prostate cancer in a transgenic adenocarcinoma mouse prostate (TRAMP) model. It has been hypothesized that the selectivity shown by bis(thiosemicarbazones) seems to be due to the higher content of $\mathrm{Cu}$ that is present in cancer tissues compared to healthy tissues. However, a more in-depth study on the targets of Cu-GTSM provides further information and better explains the observed selectivity (Denoyer et al., 2016). The obtained data associate the selectivity shown by $\mathrm{Cu}-$ GTSM to the ROS susceptibility of cancer cells as in the case of other $\mathrm{Cu}$ ionophores. In particular, TRAMP cells (TRAMP-C1) have high ROS levels together with a decreased glutathione (GSH, reduced form), making them susceptible to the action of $\mathrm{Cu}$ ionophores.

Numerous clinical trials have been performed using $\mathrm{N}^{\prime 1}, \mathrm{~N}^{\prime}$ dimethyl- $\mathrm{N}^{\prime 1}, \mathrm{~N}^{\prime 3}$-bis(phenylcarbonothioyl)

propanedihydrazide, elesclomol (ES), a well-known $\mathrm{Cu}$ ionophore, for the treatment of different types of cancer. Unlike other $\mathrm{Cu}$ ionophores, ES has not been repurposed but was discovered upon a high-throughput screening of a compound library and a SAR study against human sarcoma cell lines (Babak and Ahn, 2021). As for the mechanism of action of ES, the induction of oxidative stress that leads to cancer cell apoptosis is the generally accepted mechanism of action. Nevertheless, a series of studies have highlighted the existence of other potential targets (Hasinoff et al., 2014; Hasinoff et al., 2015). Among these, the mitochondrial enzyme ferredoxin 1 (FDX1) has been recently reported (Wang et al., 2020b). The results of clinical trials have not reported serious side effects upon the administration of ES alone or in combination with other chemotherapeutic agents (O'Day et al., 2009; Monk et al., 2018). A feature that bodes well for the 


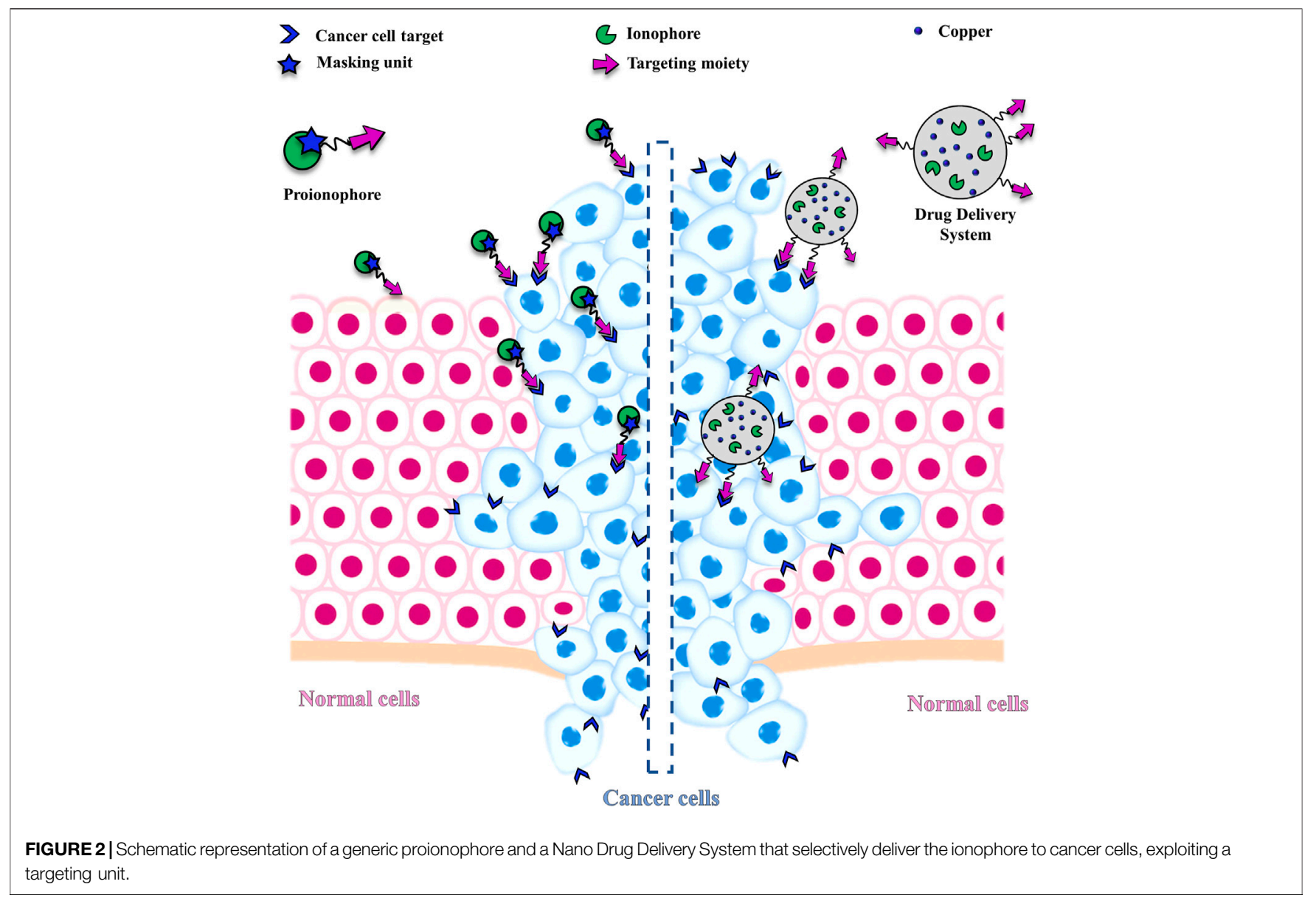

further development of this drug as most of the metal-binding compounds presents a series of side effects related to the perturbation of homeostasis of essential metal ions. ES is selective towards cancer cells, but the mechanisms that lead to this selectivity have not been clarified. It might be hypothesized that analogously to DSF or DTC, ES could target cancer cells exploiting the high levels of $\mathrm{Cu}$ or ROS. This hypothesis is supported by the data reported by Nagai et al. (Nagai et al., 2012). In brief, ES increased $\mathrm{Cu}$ levels and mitochondrial oxidative stress in the HL-60 leukemic cell line whereas it did not influence their levels in peripheral blood mononuclear cells (PBMCs). Another promising feature of ES is its ability to target resistant cancer cells including cisplatin and proteasome inhibitor resistance. The $\mathrm{ID}_{50}$ of ES in cisplatin-resistant cells was in the low nanomolar range and the antioxidant NAC was able to inhibit the effects of ES, indicating a ROS mediated mechanism of selectivity (Wangpaichitr et al., 2009).

$\mathrm{Cu}$ ionophores include HQs that have a vast variety of biological applications. The most known compound of the HQ class is 7-iodo- 5-chloro-8-hydroxyquinoline (CQ) that was first used as an antibiotic and more recently has been studied for the repurposing in different diseases ranging from neurodegenerative disorders to cancer (Oliveri, 2020). The anticancer action of $\mathrm{CQ}$ is augmented by the coadministration with $\mathrm{Cu}$ and different targets of CQ have been identified including proteasome (Daniel et al., 2005; Yu et al., 2009; Cater and Haupt, 2011; Cao et al., 2014). Among $\mathrm{Cu}-\mathrm{CQ}$ targets, it has been identified XIAP, a protein that inhibits caspases, avoiding apoptosis of cancer cells (Cater and Haupt, 2011). Cu-CQ treatment seems to cause XIAP clearance and this effect was observed only in cancer prostate cells and not in normal prostate epithelial cells, indicating a selective behavior of $\mathrm{Cu}-\mathrm{CQ}$. Although CQ has shown this slight selectivity versus cancer cells, CQ (unlike ES) presents severe side effects and has also been associated with neuropathy (SMON) (Mao and Schimmer, 2008). For these reasons, CQ must be targeted to cancer cells selectively. In addition to methods for the safe vehiculation of $C Q$, the researchers have studied other HQ derivatives that could have a greater efficacy as anticancer agents and reduced side effects. Just a few examples include 5,7-dichloro-2[(dimethylamino)methyl]-8-hydroxyquinoline (PBT2) and nitroxoline that are more active compared to $\mathrm{CQ}$ in inhibiting cancer cell proliferation in the presence of $\mathrm{Cu}$ (Jiang et al., 2011; Summers et al., 2020). This improved activity could be related to a different mechanism of action or a different cellular $\mathrm{Cu}$ distribution (Summers et al., 2020).

It is worth noting that the prolonged use of Cu-binding compounds including $\mathrm{Cu}$ ionophores can perturb the homeostasis of essential metals and therefore cause severe side 
effects in patients receiving the treatment. Although $\mathrm{Cu}$ ionophores have shown an intrinsic selectivity versus cancer cells as discussed above, there is a need to expand their therapeutic window for a safer application. So, recently, the research has focused on developing rational strategies and new treatment modalities to increase the targeting of cancer cells.

\section{STRATEGIES TO INCREASE THE SELECTIVITY OF CU IONOPHORES}

This challenging goal can be pursued, for example, through the conjugation of targeting units with $\mathrm{Cu}$ ionophores (Figure 2). The targeting moieties deliver the ionophore to cancer cells, minimizing side effects. However, the ideal solution would be the concomitant protection of the metal-binding site with the site-specific activation of the metal-ionophore function. In this context, the term proionophore refers to molecules that have to be activated to release the metal ionophore. Another possibility, that has been explored is the application of nano-drug delivery systems that release the ionophore, with or without $\mathrm{Cu}$ at the site of action (Figure 2).

\subsection{Proionophores}

What are the features of cancer cells and the strategies that can have been exploited to design $\mathrm{Cu}$ proionophores? This paragraph aims to provide the answer to such a question illustrating the advantages and disadvantages of the different methods. Moreover, the papers reported, and some experiments might indicate new avenues for the development of new and effective strategies.

Cancer cells are characterized by an altered ROS production, compared to normal cells (Trachootham et al., 2009). High expression of ROS is caused by the altered metabolism and oncogenic signaling to maintain their malignant phenotype. Therefore, cancer cells are more susceptible to a further increase of ROS above the cellular threshold level (Nogueira and Hay, 2013; Raza et al., 2017). This represents a biochemical feature of cancer cells that can be exploited to develop efficient ROS-mediated anti-cancer strategies such as photodynamic therapy (PDT) and chemodynamic therapy (CDT) (Nogueira and Hay, 2013; Raza et al., 2017). In particular, CDT based on Fenton-like chemistry to convert the less toxic $\mathrm{H}_{2} \mathrm{O}_{2}$ into highly toxic $\mathrm{OH}$ has emerged as an effective and innovative anticancer strategy. Nevertheless, the therapeutic efficacy of CDT is limited by the high expression of reducing substances (e.g., GSH) in cancer cells (Wang et al., 2020a). To increase the CDT performance, one strategy has proposed to simultaneously decrease the intracellular levels of GSH. So, the redox dyshomeostasis strategy has been proposed to design new functional molecules and nanomaterials able to disrupt redox homeostasis, augmenting intracellular oxidants and lowering antioxidants (GSH) at the same time (Tang et al., 2019; Li et al., 2020c).

$\mathrm{Cu}$ ionophores can also perturb the redox dyshomeostasis, increasing the concentration of the redox-active $\mathrm{Cu}$ and exploiting the ROS susceptibility of cancer cells. Some authors have invoked this aspect to explain the selectivity shown by some $\mathrm{Cu}$ ionophores, including DSF, CQ, and GTSM, towards cancer cells as discussed above (Safi et al., 2014; Denoyer et al., 2016; Dai et al., 2017; Ji et al., 2018). However, ROS susceptibility can be further exploited through systems activated by GSH or ROS with the concomitant depletion of antioxidants as suggested for CDT (Bao et al., 2018, 2020).

The targeting of cancer cells through oxidative stressmediating $\mathrm{Cu}$ ionophores has also been proposed for other ionophores including 3-hydroxyflavone (3-HF), 2,2'dithiodipyridine, salicylaldehyde isonicotinoyl hydrazine (Dai et al., 2017; Ji et al., 2018; Zhang et al., 2018). Cu ionophores based on a 3-hydroxy-4-keto group or a keto-enol moiety have shown a GSH-mediated redox mechanism (Dai et al., 2017, 2018). In other words, the release of $\mathrm{Cu}$ inside the cells is promoted by the GSH redox action. As a consequence, an intracellular redox imbalance was observed due to the concomitant accumulation of $\mathrm{Cu}$, depletion of $\mathrm{GSH}$, and thereby increase of ROS. In particular, 3-HF, belonging to the family of flavonoids, presented the ability to act as an efficient $\mathrm{Cu}$ ionophore and, compared to other similar systems, showed the best cytotoxicity in the presence of $\mathrm{Cu}$ against a panel of cancer cells (HepG2, SKOV3, A549) (Dai et al., 2017). Similar results were also obtained for a $\beta$-diketo analog of piperlongumine, PL-I, and salicylaldehyde isonicotinoyl hydrazine (SIH-1) (Dai et al., 2018; Ji et al., 2018). The authors managed to demonstrate through a series of elegant experiments that the release of $\mathrm{Cu}$ was GSH-dependent for all the last cited ionophores. In brief, the accumulation of $\mathrm{Cu}$ caused by the co-treatment $\mathrm{Cu}$-ionophore (PL-I or SIH-1) was detected using Atomic Absorption Spectrometer or ICP-MS, the intracellular dissociation of the $\mathrm{Cu}$ complex by GSH was demonstrated by a NIR fluorescent $\mathrm{Cu}^{+}$ probe that increased its fluorescence upon the $\mathrm{Cu}$-ionophore treatment revealing the intracellular $\mathrm{Cu}^{+}$accumulation in the cells. Further proof was given by the suppression of increased red fluorescence of the probe when cells were pretreated with L-buthio-nine-sulfoximine, a GSH synthase inhibitor. This finding highlighted the prominent role of GSH in the release of $\mathrm{Cu}$.

A mechanism with depletion of GSH can be also observed in the case of the co-treatment with 2,2' -dithiodipyridine (DPy) and $\mathrm{Cu}$ (Zhang et al., 2018). Dpy caused the intracellular accumulation of $\mathrm{Cu}$ as determined by inductively coupled plasma atomic emission spectroscopy (ICP-AES). So, the mixture $\mathrm{Cu}-\mathrm{Dpy}$ was highly cytotoxic against cancer cells, including HEPG2, HeLa, SMMC-7721, and A549 cells. On the contrary, Dpy or $\mathrm{Cu}$ alone or the simple diphenyl disulfide did not significantly affect the proliferation of cancer cells. Analogously to the other reported ionophores that exploit the ROS susceptibility of cancer cells, Cu-DPy has shown selectivity against cancerous cells since its antiproliferative effect on healthy cells (L02, BEAS-2B, and HEK 293T) was markedly less. The burst of ROS, caused by the couple $\mathrm{Cu}$-Dpy, was confirmed by using the probe $2^{\prime}, 7^{\prime}$-dichlorofluorescein diacetate DCFH-DA under a fluorescent microscope or determined by a flow cytometer. The authors hypothesized that DPy acts as a $\mathrm{Cu}$ ionophore. In brief, DPy forms a 1:1 complex with $\mathrm{Cu}$. The 


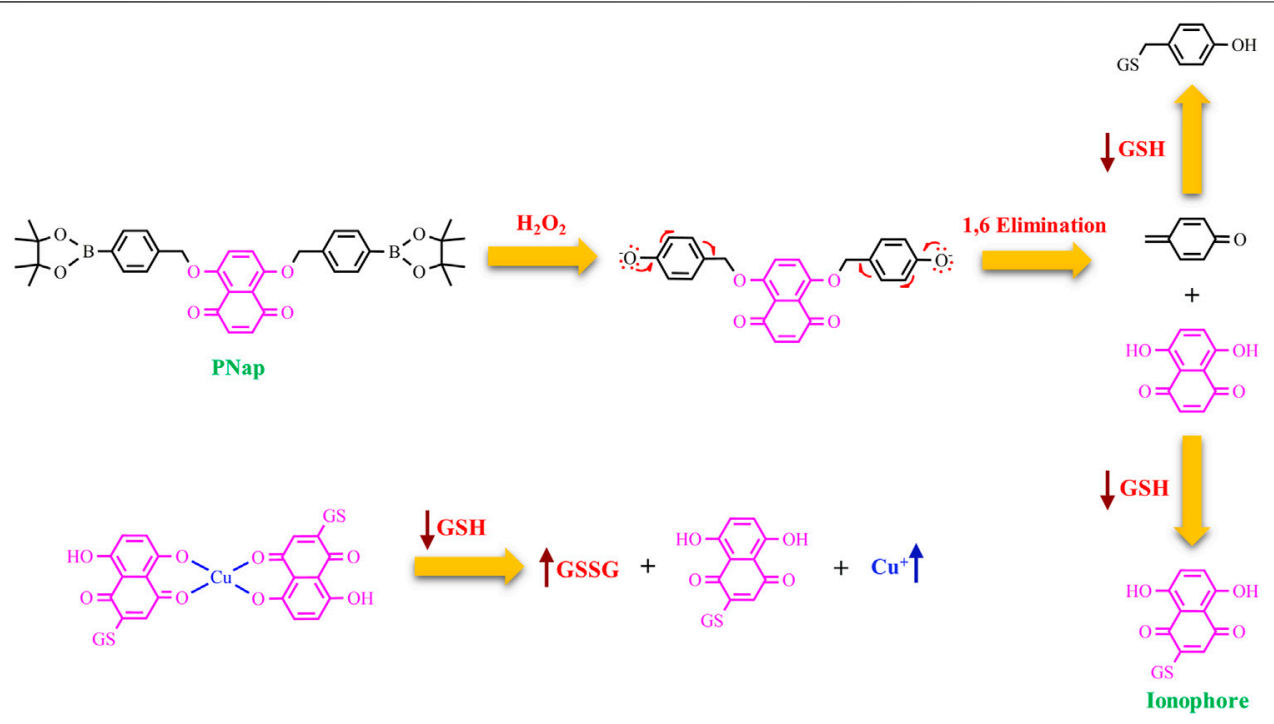

FIGURE 3 | Chemical structure of PNap and the proposed mechanism for the release of Nap upon the action of $\mathrm{H}_{2} \mathrm{O}_{2}$ and a spontaneous 1,6 benzyl elimination. Then, Nap is alkylated by GSH and acts as a Cu ionophore. The arrows highlight the processes, which occur intracellularly (GSH depletion and Cu accumulation).

complex passes through the cell membrane and the release of $\mathrm{Cu}$ is promoted by the intracellular reductants (i.e., GSH) that cleave the disulfide bridge of DPy. Then, $\mathrm{Cu}$ induces ROS formation via redox cycling reactions with thiols or other systems, further affecting the redox-regulating systems (the thioredoxin and GSH systems) and leading to the death of cancer cells mediated by oxidative stress (Zhang et al., 2018).

To further increase the cancer selectivity of $\mathrm{Cu}$ ionophores, the Zhou group has proposed the use of proionophores that can be activated exploiting the susceptibility to ROS shown by cancer cells (Bao et al., 2018, 2020). Mounting evidence suggests that proionophores could be more selective, reducing side effects that generally are associated with the administration of metal-binding compounds (Oliveri and Vecchio, 2016). 3-HF has been protected with the 2,4dinitrobenzenesulfonate group to obtain a proionophore (called PHF), which can be activated by GSH to release 3HF. PHF was preferentially cytotoxic versus the cancer cells (A549, HepG2, and HeLa) compared to its effect on healthy L02 cells. Mechanistic studies supported the following mechanism: the high levels of GSH in cancer cells activate a huge quantity of PHF. Upon the cleavage, 3-HF promotes the stress-oxidative mediated cancer cell death resulting from the accumulation of $\mathrm{Cu}$, ROS burst, and GSH depletion.

Zhou group, more recently, has proposed a more sophisticated strategy (Figure 3) with the involvement of $\mathrm{H}_{2} \mathrm{O}_{2}$ in the activation of a proionophore (Bao et al., 2020). This approach is based on the evidence that the levels of $\mathrm{H}_{2} \mathrm{O}_{2}$ are higher in cancer cells than in normal cells, making $\mathrm{H}_{2} \mathrm{O}_{2}$ a good target to develop anticancer proionophores. To validate this approach, the two phenolic hydroxyl groups of naphthazarin, a natural anticancer compound, were protected with the boronate group to obtain PNap (Figure 3). Carbon-boron oxidation is a strategy under strong development to obtain the release of cancer- targeting prodrugs (Maslah et al., 2020). PNap, administrated with $\mathrm{Cu}$, was able to selectively kill human hepatoma HepG2 and cervical carcinoma HeLa cells over human normal liver L02 and umbilical vein endothelial HUVEC cells, respectively. Moreover, the synergistic ability of Cu-PNap in killing HepG2 cells was superior to $\mathrm{Cu}-\mathrm{PHF}$. Analogously to $\mathrm{PHF}, \mathrm{Cu}-\mathrm{Nap}$ was less selective in affecting the viability of HepG2 and HeLa cells over L02 and HUVEC cells compared to Cu-PNap (Bao et al., 2020). The mechanism of action proposed is strongly supported by two pieces of evidence: 1) bathocuproine disulfonic acid disodium salt (BCS, a $\mathrm{Cu}$ chelator) suppressed the ability of Cu-PNap to kill HepG2 cells; 2) catalase (the enzyme that scavenges $\mathrm{H}_{2} \mathrm{O}_{2}$ ) also inhibited the effect of $\mathrm{Cu}-\mathrm{PNap}$.

$\mathrm{H}_{2} \mathrm{O}_{2}$ activation and the concomitant GSH depletion have also been exploited in the development of a proionophore of DTC (DQ) (Pan et al., 2019). Aryl boronic ester was used as an $\mathrm{H}_{2} \mathrm{O}_{2}$ responsive unit bound to a benzyl moiety that protects the dithiocarbamate group. The authors demonstrated that DQ was activated by $\mathrm{H}_{2} \mathrm{O}_{2}$ to release DTC upon 1,6-benzyl elimination. The results of several experiments indicate that this strategy was successful to increase selectivity. MTT assay showed that DQ $\left(\mathrm{IC}_{50}>100 \mu \mathrm{M}\right)$ was less cytotoxic than DSF against normal NIH $3 \mathrm{~T} 3$ cells $\left(\mathrm{IC}_{50}=12.5 \mu \mathrm{M}\right)$. In the presence of $\mathrm{Cu}$, the $\mathrm{IC}_{50}$ value of DQ was $1.4 \mu \mathrm{M}$ whereas that of DSF was $0.33 \mu \mathrm{M}$ versus $4 \mathrm{~T} 1$ cancer cells. Moreover, the addition of exogenous $\mathrm{H}_{2} \mathrm{O}_{2}$ enhanced the $\mathrm{IC}_{50}$ of DQ whereas did not affect the cytotoxicity of DSF $\left(\mathrm{IC}_{50}=0.80 \mu \mathrm{M}\right)$. The authors correctly highlighted that DSF releases two DTC units and this explains the doubled activity of DSF compared to DQ in the presence of $\mathrm{H}_{2} \mathrm{O}_{2}$. Finally, the value of DSF in the presence of $\mathrm{Cu}$ in normal cells was similar to that in cancer cells while the proionophore was selective with an increased $\mathrm{IC}_{50}$ of 5 times in normal cells. Furthermore, the measurements of the GSH content revealed a decrease in GSH level upon the treatment with DQ 


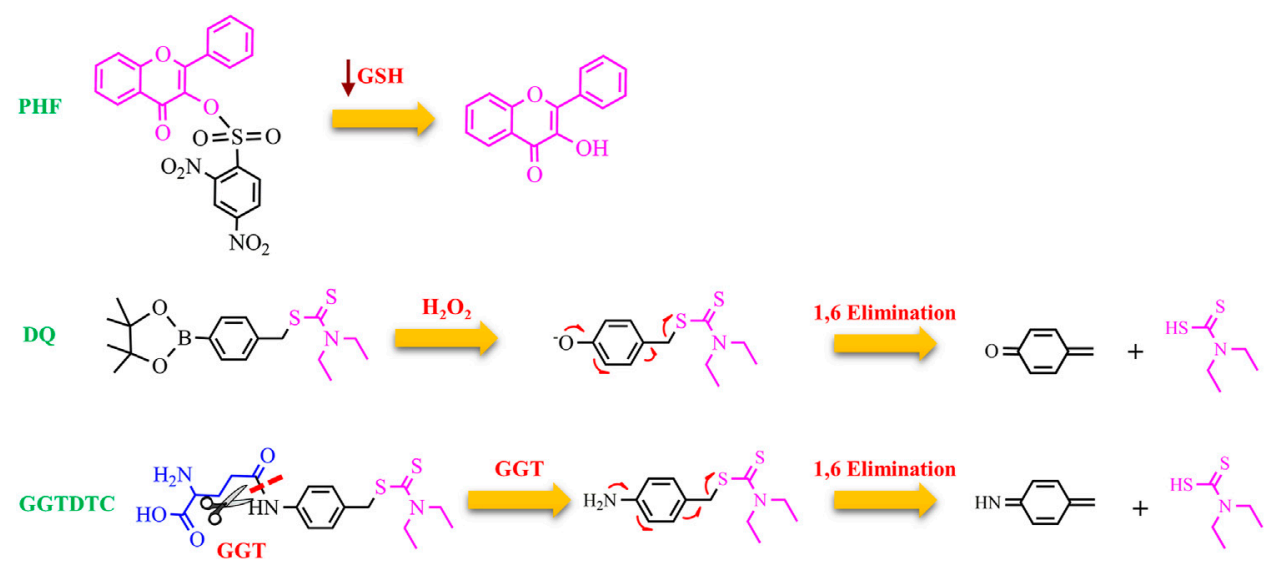

FIGURE 4 | Chemical structure of PHQ, DQ, and GGTDTC and the proposed mechanism for the release of the active ionophores (3-HF and DTC).

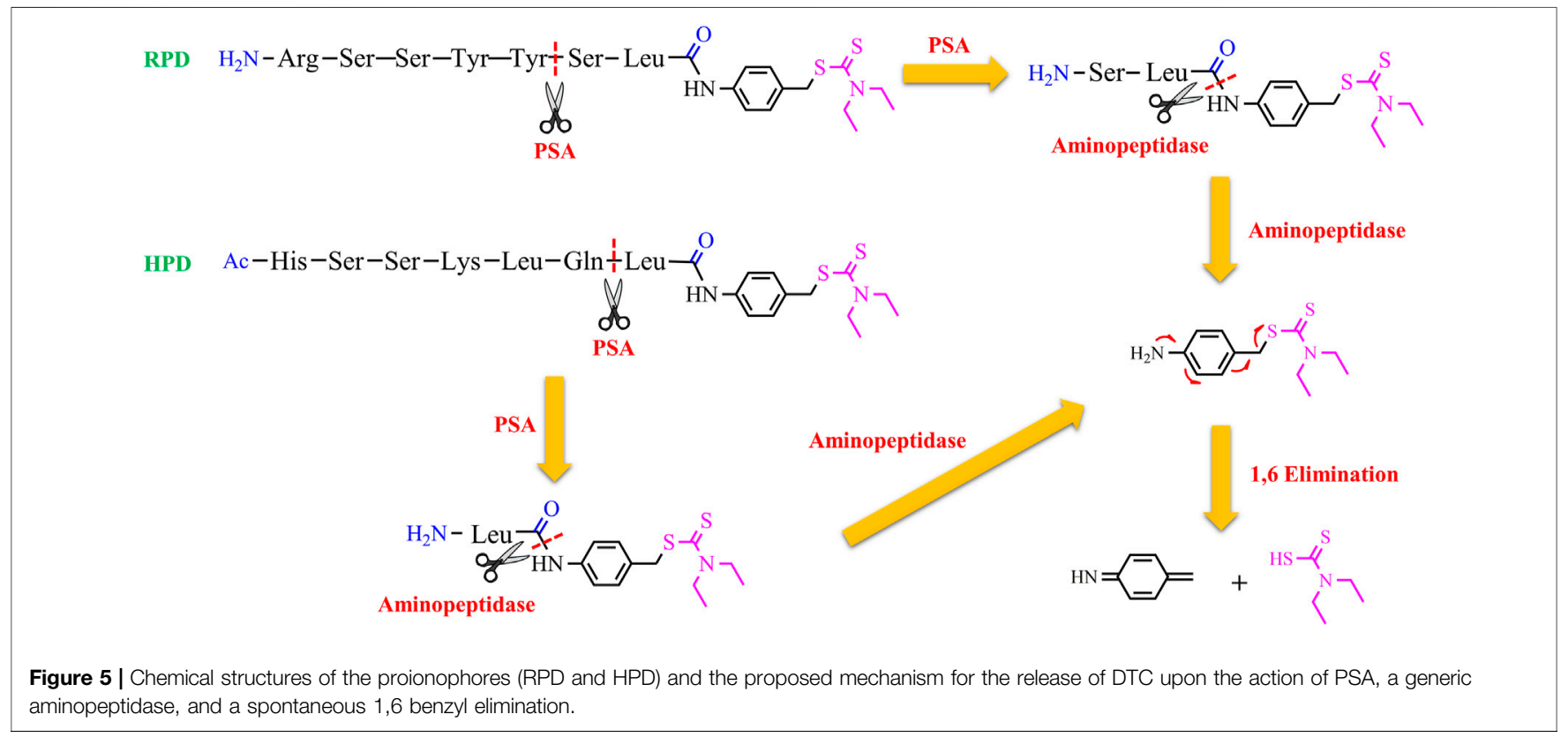

whereas DSF did not influence the GSH/GSSG ratio (Pan et al., 2019). Overall, DQ is able to target selectively cancer cells exploiting the high concentration of $\mathrm{H}_{2} \mathrm{O}_{2}$ and amplifying oxidative stress because of the release of quinone methide, a GSH scavenger.

The site-specific activation of prodrugs can be also obtained by enzyme prodrug therapies (EPT) (Walther et al., 2017). In these approaches, prodrugs are typically designed to achieve a quantitative release of the drug upon the action of a specific enzyme. In particular, one of the EPT strategies consists in exploiting enzymes that: 1) are only found in cancer cells; 2) are overexpressed in cancer cells; 3) change their cellular localization during the cell malignant transformation; 4) change their function in malignant cells (Walther et al., 2017).
Gamma-glutamyl transferase (GGT) is a cell-surface enzyme localized in a wide distribution of tissues including the liver. It is involved in the metabolism of GSH. In healthy cells, GGT only cleaves substrates in ductal fluids whereas GGT, expressed in cancer cells, can hydrolyze GSH and other substrates present the interstitial fluid and blood (Hanigan, 2014). Therefore, GGT plays a key role to provide additional cysteine for the intracellular synthesis of GSH, one of the main components of the cellular redox buffering system. It is therefore not surprising that many cancer cell lines overexpress GGT, and, moreover, high GGT levels seem to correlate with severe outcomes of the disease. In this context, DTC was functionalized with a $\gamma$-glutamate residue through a self-immolative p-amino benzyl linker to form GGTDTC (Bakthavatsalam et al., 2018). A series of 
elegant experiments have shown that: 1) the conjugate was not able to chelate $\mathrm{Cu}$, as demonstrated by calcein competition assays; 2) the conjugate could act as a proionophore because GGT hydrolyzed it, releasing the metal-binding compound; 3) GGTDTC, in the presence of GGT and $\mathrm{Cu}$, formed $\mathrm{Cu}(\mathrm{DTC})_{2}$ as demonstrated by mass spectrometry; 4) GGTDTC has a higher affinity for GGT compared to GSH as highlighted by competition experiments in the presence of the colorimetric substrate L-glutamic acid $\gamma$-(p-nitroanilide); 5) GGTDTC was significantly cleaved in $22 \mathrm{Rv} 1$ cell line, a GGT-positive and aggressive prostate cancer cell line; 6) the GGT inhibitor Acivicin hindered the hydrolysis of GGTDTC; 7) GGTDTC was stable in PWR-1E cells, that do not exhibit GGT activity; 8) the antiproliferative efficacy of GGTDTC correlated with the GGT activity. As a consequence, the $\mathrm{IC}_{50}$ of GGTDTC was lower $\left(\mathrm{IC}_{50}=800 \mathrm{nM}\right.$ at $\left.24 \mathrm{~h}\right)$ in cells with high levels of GGT (22Rv1 and $\mathrm{LNCaP})$ and higher in normal prostate PWR-1E cells $\left(\mathrm{IC}_{50}=\right.$ $15 \mu \mathrm{M}$ at $24 \mathrm{~h}$ ) (Bakthavatsalam et al., 2018). All these findings support the selective targeting of cancer cells by GGTDTC with the following mechanism of action: GGT cleaves the amide bond, inducing the 1,6 benzyl elimination of the p-amino benzyl linker. The released DTC may chelate $\mathrm{Cu}$ in the proximity of GGTproducing cells and lead to the intracellular accumulation of $\mathrm{Cu}$, triggering cancer cell death (Figure 4).

Nevertheless, GGT is not only overexpressed in some aggressive cancer cells but is also upregulated in the liver. So, it is necessary to find more selective targets for cancer cells. Prostate-specific antigen (PSA) could be considered a good choice to target selectively prostate cancer cells. PSA is a $34-\mathrm{kD}$ glycoprotein with a serine protease activity and is overexpressed in prostate cancer cells (Moradi et al., 2019). PSA is active in the prostate, but, it is released as an inactivated form bound to al-antichymotrypsin in the serum (Hsieh and Cooperman, 2002). This implies that a prodrug, activated by PSA, may release the drug only in the prostate. Taking this into account, two substrates (RSSYYS and HSSKLQ) of PSA were conjugated to DTC through a leucine spacer and a self-immolative $\mathrm{p}$-amino benzyl linker to generate two proionophores RPD and HPD (Bakthavatsalam et al., 2020). The conjugates could have a series of advantages: the thiol group of DTC is masked so 1) it can not bind metal ions, avoiding systemic chelation and the associated sideeffects; 2) it does not react with protein and other cellular thiols; 3) the conjugates are more stable than DTC that decomposes in other metabolites with off-targets. It has demonstrated that PSA cleaved HPD between Gln and Leu amino acids whereas RPD was cleaved between Tyr and Ser as confirmed by mass spectrometry studies. Cleavage experiments in lysates indicated that HPD was more selective toward PSA-producing cells and was stable against aspecific proteases. Moreover, the anticancer activity of these proionophores was investigated in androgen-sensitive human prostate adenocarcinoma cells (LNCaP), which express PSA, and androgen-independent PC3 cell lines that do not express PSA (Tai et al., 2011). The cells were treated with HPD or RPD in the presence of $\mathrm{Cu}$. RPD was found to have similar $\mathrm{IC}_{50}$ in both cell lines
( $\mathrm{IC}_{50}$ was $0.77 \mu \mathrm{M}$ in $\mathrm{LNCaP}$ and $1.8 \mu \mathrm{M}$ in PC3 cells). The $\mathrm{D}$-Ser version of RPD and $\mathrm{Cu}$ did not display antiproliferative activity at the same concentrations, confirming that the cleavage is necessary for the activity of RPD. However, the $\mathrm{IC}_{50}$ values shown by RPD suggest that the system is nonselectively cleaved by PSA. Indeed, the RSSYYS peptide could be a substrate of other chymotrypsin-like serine proteases. On the other hand, HPD displayed an $\mathrm{IC}_{50}$ of 1.4 and $11.2 \mu \mathrm{M}$ in LNCaP and PC3 cells, respectively. This finding suggests that HPD was more selective than RPD, further confirming the results of the lysate analysis (Bakthavatsalam et al., 2020). Overall, PSA induces the release of DTC, cleaving the peptide. Then, non-specific aminopeptidases remove the final residues to trigger the 1,6-benzyl elimination of the amino benzyl linker leading to the release of DTC (Figure 5). The latter can chelate $\mathrm{Cu}$ present in the tumor tissue and induce oxidative stress-mediated cancer cell death. In particular, prostate cancer cells are known to accumulate $\mathrm{Cu}$, a factor that can further improve selectivity.

Glycoconjugation has also been considered an appealing strategy to target cancer cells (Fu et al., 2020). Malignant cells significantly enhance glucose uptake and glycolysis to maintain their high rate of proliferation. This phenomenon, named "the Warburg effect", is one of the hallmarks of cancer. As a consequence, glucose transporters (i.e., GLUT1) are overexpressed in several human cancers (Szablewski, 2013). Just to give a few examples, anticancer platinum (Pt) systems with appended glucose moieties were active against a panel of cancer cells and accumulated preferentially in tumor cells compared to normal cells (Patra et al., 2016b; Ma et al., 2016). Moreover, an elegant SAR study has demonstrated that the conjugation of the $\mathrm{Pt}$ moiety to different positions of D-glucose influences the cellular uptake mediated by GLUT and cytotoxicity of the glycoconjugates (Patra et al., 2016a). In this context, $\mathrm{Cu}$ ionophores have been conjugated to glucose and other saccharides to obtain proionophores (Oliveri, 2015). The $\mathrm{Cu}$ binding site of these compounds is protected by a glycosidic bond with the sugar unit, so this linkage should be cleaved for the chelation of $\mathrm{Cu}$. The synthesis of different compounds and their evaluation have highlighted the following points: 1) the glucose-HQ compounds were directly hydrolyzed in cancer cells whereas the analogous galactoconjugated systems required the external administration of $\beta$-galactosidase; 3 ) the action of $\beta$ glucosidase was fundamental to determine the anticancer effects of the HQ glucoconjugates as demonstrated by the increased $\mathrm{IC}_{50}$ in the presence of a $\beta$-glucosidase inhibitor; 4 ) the HQ glucosides released HQs, that induced cuproptosis through a ionophore-mediated mechanism as indicated by the decreased $\mathrm{IC}_{50}$ when administrated together with $\mathrm{Cu} ; 5$ ) the presence of different substituents on the HQ moiety influenced the capacity of the glucosides to be cleaved by $\beta$-glucosidase, therefore docking studies are required to predict if the enzyme can promote the quantitative release of the HQ derivative from the glycoconjugates. The hypothesized mechanism of action for HQ proionophores lies in the active internalization of these conjugates into cancer cells through specific transporters, the release of the 
HQ derivative, and the induction of cuproptosis of cancer cells upon the intracellular accumulation of $\mathrm{Cu}$.

Glycoconjugation could be exploited in targeting the asialoglycoprotein receptor (ASGPR) since this strategy has displayed increased tumor accumulation and anticancer activity of the systems conjugated with sugar units recognized by ASGPR (D'Souza and Devarajan, 2015). As for Cu ionophores, this approach has been currently evaluated only for Cu-GTSM for the application in diseases characterized by $\mathrm{Cu}$ deficiency (Su et al., 2018). Future development of this strategy could evaluate other applications, for example, in the cancer area.

\subsection{Nano-Drug Delivery Systems}

Another possible approach, which has been explored to target selectively cancer cells with $\mathrm{Cu}$ ionophores, involves the use of drug delivery systems (DDSs). Nanoparticle systems preferentially accumulate in cancer tissues rather than healthy ones because of the Enhanced Permeability and Retention (EPR) effect. Moreover, active targeting can be obtained by modifying appropriately the DDS using, for example, cancer-specific targeting ligands or thermosensitive liposomes and mild hyperthermia to reduce undesired off-target effects (Figure 2).

This strategy has been investigated by Gaal et al. that have used a thermosensitive liposomal formulation loaded with $\mathrm{Cu}$ and neocuproine (Gaál et al., 2020). The authors also compared this system with analogous thermoresistant DDSs. Even though neocuproine is known as a $\mathrm{Cu}(\mathrm{I})$ chelator, the data showed that both DDSs induced intracellular $\mathrm{Cu}$ accumulation and in vitro and in vivo toxicity in $\mathrm{BALB} / \mathrm{c}$ mice engrafted with C26 cancer cells. Nevertheless, the effect of the thermosensitive formulation was higher compared to the insensitive system. Moreover, mild hyperthermia treatment allowed to reduce the administrated dose when the thermosensitive liposome was used (Gaál et al., 2020).

Moreover, DDSs have been particularly investigated for the selective delivery of DSF to try to overcome the drawbacks associated with its administration (McMahon et al., 2020).

Selective polymeric nanoparticles of DTC (LDNP) were obtained, conjugating lactobionic acid (LBA) and DTC to poly [(2-(pyridin-2-yldisulfanyl) ethyl acrylate)-co-[poly(ethylene glycol)]] (PDA-PEG), endowed of several pyridine-2-thiol groups, via a thiol-disulfide exchange reaction. These polymers forms nanoparticles with a size of $30 \mathrm{~nm}$ that are stable in serum, suggesting good stability in blood. Lactobionic acid acted as the targeting moiety because it was recognized by a $\beta$-D-galactose lectin receptor overexpressed in some cancer cells, such as liver and ovarian cancers including SKOV-3. The recognition by the receptor remarkably increased the cellular uptake of LDNP compared to analogous nanoparticles without the lactobionic acid as demonstrated by confocal microscopy. This enhanced cellular uptake caused, in turn, higher efficiency in killing cancer cells, in penetrating and dissolving a tumor spheroid model, and, finally, in inhibiting a metastatic ovarian cancer in vivo. The selectivity of these systems was demonstrated by low toxicity in normal liver cells and the lack of side effects found in mice treated with LDNP. It has been hypothesized, based on in vitro data in presence of GSH, that LDNP releases DTC in the reducing intracellular environment and the active ionophore can bind $\mathrm{Cu}$ and lead to cancer cell death. The hypothesis is supported by the evidence that in absence of $\mathrm{Cu}$, all the tested systems significantly failed to kill cancer cells (He et al., 2018). Overall, the data indicated that $\mathrm{Cu}$-LDNP nanoparticles could be a selective and safe tool for the treatment of cancers overexpressing the galactose receptor. The disadvantage of this DDS relies on the different route of $\mathrm{Cu}$ administration as $\mathrm{Cu}$ are not delivered together with DSF.

Since DSF is rapidly degraded in biological fluids and its activity is increased by $\mathrm{Cu}$, DDSs able to selectively transport DSF at the tumor cells with the concomitant release of $\mathrm{Cu}$ could be more advantageous. To validate this hypothesis, different nanoparticle systems have been developed (Chen et al., 2018; Wu et al., 2019; Chang et al., 2020). Li group has proposed metalorganic nanoparticles (MONs) prepared through a method that has been defined as "Stabilized Metal Ion Ligand Nanocomplex (SMILE) technology" (Wehbe et al., 2018). This method provided interesting results, for example, with biomimetic albumindecorated Cu-DTC MONs (Chang et al., 2020). These particles were prepared by mixing $\mathrm{Cu}$ and DTC in the presence of albumin (BSA) using a microfluidic device. The formulation was rather homogeneous with a size inferior to $100 \mathrm{~nm}$. MONs prepared with BSA were stable in serum and could target selectively cancer cells exploiting the EPR effect but also the SPARC receptor, which binds BSA and is overexpressed in cancer cells. As a consequence of the accumulation in the tumor site, the BSA Cu-DTC MONs showed the highest anticancer activity and a good tolerance compared to the other tested controls (Chang et al., 2020). Recent advancement of this DDS uses the proionophore DQ in building the nano delivery system and strengthening the toxicity of DTC with a combination of therapies (Kang et al., 2021). In this system, the activation of DQ is increased by the ROS formed by NIR laser action, $\mathrm{Cu}$ is also delivered in situ together with DSF. The toxicity of Cu-DSF is exacerbated by the tumor ROS amplification in response to NIR light treatment and, the induction of immunogenic cell death with concomitant GSH depletion (Kang et al., 2021).

Pegylated mesoporous silica nanoparticles doped with $\mathrm{Cu}$ and DSF were also tested in vitro and in vivo with good results. The acidic condition of the tumor environment induced the degradation of the nanoparticles with the concomitant release of DSF and $\mathrm{Cu}$, whereas the nanosystem was stable at physiological $\mathrm{pH}$. Upon the release, DSF reacted with $\mathrm{Cu}$ and the triggered Fenton-like chemistry also led to the formation of radical ROS species. This amplified the cytotoxic effects of $\mathrm{Cu}$ DTC as confirmed by the experiments in $4 \mathrm{~T} 1$ tumor-bearing female BALB/C nude mice. Indeed, the efficacy of the drug delivery system was indicated by the high inhibition rate of $71.4 \%$, compared to DSF alone that did not show chemotherapeutic efficacy (Wu et al., 2019).

Finally, DDSs have also been proposed for CQ or other HQ derivatives but we are far from achieving analogous results to those obtained for DSF (Wang et al., 2013; Weerasuriya et al., 2017; Wehbe et al., 2018; Campos et al., 2020). Nevertheless, the development of a selective DDS for CQ could be a turning point 
to solve the toxicity problems that led to the CQ withdrawal from the market.

\section{CONCLUSION}

The discovery of numerous additional pathways that involve $\mathrm{Cu}$ and $\mathrm{Cu}$-dependent proteins is proof of the extraordinary progress in the field. In this respect, it suffices to note that two new terms "cuproplasia" and "cuproptosis" have been recently used to indicate unique biological processes triggered by $\mathrm{Cu}$ action. In this context, $\mathrm{Cu}$ ionophores that could selectively induce cuproptosis may well succeed in overcoming the limits of traditional anticancer drugs. Despite a great number of studies, there is a poor understanding of how $\mathrm{Cu}$ ionophores act as selective anticancer agents. Generally, the most accepted theories suggest that $\mathrm{Cu}$ ionophores exploit the massive presence of $\mathrm{Cu}$ in tumor tissue, alternatively, they take advantage of cancer cell susceptibility due to oxidative stress. Nevertheless, many questions remain regarding these mechanisms and there is the need to address these questions to better exploit their action in arresting cancer progression. However, their intrinsic selectivity can be expanded to obtain a larger therapeutic window. In this context, the results obtained suggested that the most efficient systems are the proionophores that are selectively activated in tumor cells. Most of the studied systems are preferentially accumulated or

\section{REFERENCES}

Allensworth, J. L., Evans, M. K., Bertucci, F., Aldrich, A. J., Festa, R. A., Finetti, P., et al. (2015). Disulfiram (DSF) Acts as a Copper Ionophore to Induce Copperdependent Oxidative Stress and Mediate Anti-tumor Efficacy in Inflammatory Breast Cancer. Mol. Oncol. 9, 1155-1168. doi:10.1016/J. MOLONC.2015.02.007

Aubert, L., Nandagopal, N., Steinhart, Z., Lavoie, G., Nourreddine, S., Berman, J., et al. (2020). Copper Bioavailability Is a KRAS-specific Vulnerability in Colorectal Cancer. Nat. Commun. 11, 1-15. doi:10.1038/s41467-020-17549-y

Babak, M. V., and Ahn, D. (2021). Modulation of Intracellular Copper Levels as the Mechanism of Action of Anticancer Copper Complexes: Clinical Relevance. Biomedicines 9, 852. doi:10.3390/biomedicines 9080852

Bakthavatsalam, S., Sleeper, M. L., Dharani, A., George, D. J., Zhang, T., and Franz, K. J. (2018). Leveraging $\gamma$-Glutamyl Transferase to Direct Cytotoxicity of Copper Dithiocarbamates against Prostate Cancer Cells. Angew. Chem. 130, 12962-12966. doi:10.1002/ange.201807582

Bakthavatsalam, S., Wiangnak, P., George, D. J., Zhang, T., and Franz, K. J. (2020). Dithiocarbamate Prodrugs Activated by Prostate Specific Antigen to Target Prostate Cancer. Bioorg. Med. Chem. Lett. 30, 127148. doi:10.1016/j. bmcl.2020.127148

Baltaci, A. K., Dundar, T. K., Aksoy, F., and Mogulkoc, R. (2017). Changes in the Serum Levels of Trace Elements before and after the Operation in Thyroid Cancer Patients. Biol. Trace Elem. Res. 175, 57-64. doi:10.1007/s12011-0160768-2

Bao, X.-Z., Dai, F., Li, X.-R., and Zhou, B. (2018). Targeting Redox Vulnerability of Cancer Cells by Prooxidative Intervention of a Glutathione-Activated $\mathrm{Cu}$ (II) Pro-ionophore: Hitting Three Birds with One Stone. Free Radic. Biol. Med. 124, 342-352. doi:10.1016/j.freeradbiomed.2018.06.021

Bao, X.-Z., Wang, Q., Ren, X.-R., Dai, F., and Zhou, B. (2020). A Hydrogen Peroxide-Activated $\mathrm{Cu}(\mathrm{II})$ Pro-ionophore Strategy for Modifying Naphthazarin as a Promising Anticancer Agent with High Selectivity for activated in cancer cells, exploiting a metabolic feature of cancer cells (i.e. ROS susceptibility, glucose avidity, etc). The choice of the targeting unit of the proionophores or nanodrug delivery systems is crucial in designing these systems to deliver the cancer drug exclusively to the cancer tissue. In other words, the next generation of selective $\mathrm{Cu}$ ionophores should exploit targeting units that can be recognized only by specific receptors that are exclusively found in a particular type of cancer cells (i.e. prostate or breast cancer cells). $\mathrm{Cu}$ proionophores and nano-drug delivery systems are at the early stage of development, but the obtained results show promise for developing innovative therapies that can expand the existing landscape of cancer chemotherapeutics.

\section{AUTHOR CONTRIBUTIONS}

VO wrote, discussed, reviewed the manuscript, designed and created figures.

\section{ACKNOWLEDGMENTS}

The author thanks the Università degli Studi di Catania (Piano di incentivi per la ricerca di Ateneo 2020/2022 Pia.ce.ri.-Linea 2 and 3, Projects: SELECTION and 3N-Oracle), the Italian Ministero dell'Università e della Ricerca.

Generating ROS in HepG2 Cells over in L02 Cells. Free Radic. Biol. Med. 152, 597-608. doi:10.1016/j.freeradbiomed.2019.12.001

Basu, S., Singh, M. K., Singh, T. B., Bhartiya, S. K., Singh, S. P., and Shukla, V. K. (2013). Heavy and Trace Metals in Carcinoma of the Gallbladder. World J. Surg. 37, 2641-2646. doi:10.1007/s00268-013-2164-9

Campos, I. M. F., Barros, I. R., Ferraz, H. C., and Pinto, J. C. (2020). P(MMAco-AA) Nanoparticles Loaded with Clioquinol and Functionalized with TAT Peptide. Macromol. React. Eng. 14, 1900046. doi:10.1002/MREN. 201900046

Cao, B., Li, J., Zhou, X., Juan, J., Han, K., Zhang, Z., et al. (20142014). Clioquinol Induces Pro-death Autophagy in Leukemia and Myeloma Cells by Disrupting the mTOR Signaling Pathway. Sci. Rep. 4 (4), 1-7. doi:10.1038/srep05749

Cater, M. A., and Haupt, Y. (2011). Clioquinol Induces Cytoplasmic Clearance of the X-Linked Inhibitor of Apoptosis Protein (XIAP): Therapeutic Indication for Prostate Cancer. Biochem. J. 436, 481-491. doi:10.1042/BJ20110123

Cater, M. A., Pearson, H. B., Wolyniec, K., Klaver, P., Bilandzic, M., Paterson, B. M., et al. (2013). Increasing Intracellular Bioavailable Copper Selectively Targets Prostate Cancer Cells. ACS Chem. Biol. 8, 1621-1631. doi:10.1021/ cb400198p

Cen, D., Brayton, D., Shahandeh, B., Meyskens, F. L., and Farmer, P. J. (2004). Disulfiram Facilitates Intracellular $\mathrm{Cu}$ Uptake and Induces Apoptosis in Human Melanoma Cells. J. Med. Chem. 47, 6914-6920. doi:10.1021/ JM049568Z/SUPPL_FILE/JM049568ZSI20040929_085559.PDF

Chang, Y., Jiang, J., Chen, W., Yang, W., Chen, L., Chen, P., et al. (2020). Biomimetic Metal-Organic Nanoparticles Prepared with a 3D-Printed Microfluidic Device as a Novel Formulation for Disulfiram-Based Therapy against Breast Cancer. Appl. Mater. Today 18, 100492. doi:10.1016/J.APMT. 2019.100492

Chen, D., Cui, Q. C., Yang, H., and Dou, Q. P. (2006). Disulfiram, a Clinically Used Antialcoholism Drug and Copper-Binding Agent, Induces Apoptotic Cell Death in Breast Cancer Cultures and Xenografts via Inhibition of the Proteasome Activity. Cancer Res. 66, 10425-10433. doi:10.1158/0008-5472.CAN-06-2126 
Chen, F., Wang, J., Chen, J., Yan, L., Hu, Z., Wu, J., et al. (2019). Serum Copper and Zinc Levels and the Risk of Oral Cancer: A New Insight Based on Large-scale Case-Control Study. Oral Dis. 25, 80-86. doi:10.1111/odi.12957

Chen, W., Yang, W., Chen, P., Huang, Y., and Li, F. (2018). Disulfiram Copper Nanoparticles Prepared with a Stabilized Metal Ion Ligand Complex Method for Treating Drug-Resistant Prostate Cancers. ACS Appl. Mater. Inter., 10, 41118-41128. doi:10.1021/ACSAMI.8B14940

D'Souza, A. A., and Devarajan, P. V. (2015). Asialoglycoprotein Receptor Mediated Hepatocyte Targeting - Strategies and Applications. J. Controlled Release 203, 126-139. doi:10.1016/j.jconrel.2015.02.022

Dai, F., Yan, W.-J., Du, Y.-T., Bao, X.-Z., Li, X.-Z., and Zhou, B. (2017). Structural Basis, Chemical Driving Forces and Biological Implications of Flavones as $\mathrm{Cu}(\mathrm{II})$ Ionophores. Free Radic. Biol. Med. 108, 554-563. doi:10.1016/j. freeradbiomed.2017.04.023

Dai, F., Yuan, C.-H., Ji, Y., Du, Y.-T., Bao, X.-Z., Wu, L.-X., et al. (2018). Keto-enolbased Modification on Piperlongumine to Generate a Potent $\mathrm{Cu}$ (II) Ionophore that Triggers Redox Imbalance and Death of HepG2 Cells. Free Radic. Biol. Med. 120, 124-132. doi:10.1016/j.freeradbiomed.2018.03.029

Daniel, K. G., Chen, D., Orlu, S., Cui, Q. C., Miller, F. R., and Dou, Q. P. (2005). Clioquinol and Pyrrolidine Dithiocarbamate Complex with Copper to Form Proteasome Inhibitors and Apoptosis Inducers in Human Breast Cancer Cells. Breast Cancer Res. 7, R897-R908. doi:10.1186/bcr1322

Denoyer, D., Masaldan, S., La Fontaine, S., and Cater, M. A. (2015). Targeting Copper in Cancer Therapy: 'Copper that Cancer'. Metallomics 7, 1459-1476. doi:10.1039/C5MT00149H

Denoyer, D., Pearson, H. B., Clatworthy, S. A. S., Smith, Z. M., Francis, P. S., Llanos, R. M., et al. (2016). Copper as a Target for Prostate Cancer Therapeutics: Copper-Ionophore Pharmacology and Altering Systemic Copper Distribution. Oncotarget 7, 37064-37080. doi:10.18632/oncotarget.9245

Ding, X., Jiang, M., Jing, H., Sheng, W., Wang, X., Han, J., et al. (2015). Analysis of Serum Levels of 15 Trace Elements in Breast Cancer Patients in Shandong, China. Environ. Sci. Pollut. Res. 22, 7930-7935. doi:10.1007/s11356-0143970-9

Donnelly, P. S., Liddell, J. R., Lim, S., Paterson, B. M., Cater, M. A., Savva, M. S., et al. (2012). An Impaired Mitochondrial Electron Transport Chain Increases Retention of the Hypoxia Imaging Agent Diacetylbis(4methylthiosemicarbazonato)copperII. Proc. Natl. Acad. Sci. 109, 47-52. doi:10.1073/PNAS.1116227108/-/DCSUPPLEMENTAL

Ekinci, E., Rohondia, S., Khan, R., and Dou, Q. P. (2019). Repurposing Disulfiram as an Anti-cancer Agent: Updated Review on Literature and Patents. Pra 14, 113-132. doi:10.2174/1574892814666190514104035

Falls-Hubert, K. C., Butler, A. L., Gui, K., Anderson, M., Li, M., Stolwijk, J. M., et al. (2020). Disulfiram Causes Selective Hypoxic Cancer Cell Toxicity and RadioChemo-Sensitization via Redox Cycling of Copper. Free Radic. Biol. Med. 150, 1-11. doi:10.1016/j.freeradbiomed.2020.01.186

Fu, J., Yang, J., Seeberger, P. H., and Yin, J. (2020). Glycoconjugates for Glucose Transporter-Mediated Cancer-specific Targeting and Treatment. Carbohydr. Res. 498, 108195. doi:10.1016/J.CARRES.2020.108195

Gaál, A., Garay, T. M., Horváth, I., Máthé, D., Szöllösi, D., Veres, D. S., et al. (2020). Development and In Vivo Application of a Water-Soluble Anticancer Copper Ionophore System Using a Temperature-Sensitive Liposome Formulation. Pharmaceutics 12, 466. doi:10.3390/pharmaceutics12050466

Ge, E. J., Bush, A. I., Casini, A., Cobine, P. A., Cross, J. R., DeNicola, G. M., et al. (2021). Connecting Copper and Cancer: from Transition Metal Signalling to Metalloplasia. Nat. Rev. Cancer 22, 102-113. 1-12. doi:10.1038/s41568-02100417-2

Gunjan, D., ShalimarNadda, N., Nadda, N., Kedia, S., Nayak, B., Paul, S. B., et al. (2017). Hepatocellular Carcinoma: An Unusual Complication of Longstanding Wilson Disease. J. Clin. Exp. Hepatol. 7, 152-154. doi:10.1016/J.JCEH.2016.09.012

Gupta, S. K., Shukla, V. K., Vaidya, M. P., Roy, S. K., and Gupta, S. (1993). Serum and Tissue Trace Elements in Colorectal Cancer. J. Surg. Oncol. 52, 172-175. doi:10.1002/JSO.2930520311

Hanigan, M. H. (2014). Gamma-Glutamyl Transpeptidase. Adv. Cancer Res. 122, 103-141. doi:10.1016/B978-0-12-420117-0.00003-7

Hasinoff, B. B., Wu, X., Yadav, A. A., Patel, D., Zhang, H., Wang, D.-S., et al. (2015). Cellular Mechanisms of the Cytotoxicity of the Anticancer Drug Elesclomol and its Complex with $\mathrm{Cu}(\mathrm{II})$. Biochem. Pharmacol. 93, 266-276. doi:10.1016/J.BCP. 2014.12.008
Hasinoff, B. B., Yadav, A. A., Patel, D., and Wu, X. (2014). The Cytotoxicity of the Anticancer Drug Elesclomol Is Due to Oxidative Stress Indirectly Mediated through its Complex with $\mathrm{Cu}(\mathrm{II})$. J. Inorg. Biochem. 137, 22-30. doi:10.1016/J. JINORGBIO.2014.04.004

Hassani, S., Ghaffari, P., Chahardouli, B., Alimoghaddam, K., Ghavamzadeh, A., Alizadeh, S., et al. (2018). Disulfiram/copper Causes ROS Levels Alteration, Cell Cycle Inhibition, and Apoptosis in Acute Myeloid Leukaemia Cell Lines with Modulation in the Expression of Related Genes. Biomed. Pharmacother. 99, 561-569. doi:10.1016/J.BIOPHA.2018.01.109

He, H., Markoutsa, E., Li, J., and Xu, P. (2018). Repurposing Disulfiram for Cancer Therapy via Targeted Nanotechnology through Enhanced Tumor Mass Penetration and Disassembly. Acta Biomater. 68, 113-124. doi:10.1016/J. ACTBIO.2017.12.023

Hickey, J. L., Crouch, P. J., Mey, S., Caragounis, A., White, J. M., White, A. R., et al. (2020b). Copper(ii) Complexes of Hybrid HydroxyquinolineThiosemicarbazone Ligands: GSK3 $\beta$ Inhibition Due to Intracellular Delivery of Copper. Dalton Trans. 40, 1338-1347. doi:10.1039/c0dt01176b

Hothi, P., Martins, T. J., Chen, L., Deleyrolle, L., Yoon, J.-G., Reynolds, B., et al. (2012). High-Throughput Chemical Screens Identify Disulfiram as an Inhibitor of Human Glioblastoma Stem Cells. Oncotarget 3, 1124-1136. doi:10.18632/ ONCOTARGET.707

Hsieh, M.-C., and Cooperman, B. S. (2002). Inhibition of Prostate-specific Antigen (PSA) by a1-Antichymotrypsin: Salt-dependent Activation Mediated by a Conformational Change. Biochemistry 41, 2990-2997. doi:10.1021/bi0117450

Hunsaker, E. W., and Franz, K. J. (2019). Emerging Opportunities to Manipulate Metal Trafficking for Therapeutic Benefit. Inorg. Chem. 58, 13528-13545. doi:10.1021/acs.inorgchem.9b01029

Ishida, S., Andreux, P., Poitry-Yamate, C., Auwerx, J., and Hanahan, D. (2013). Bioavailable Copper Modulates Oxidative Phosphorylation and Growth of Tumors. Proc. Natl. Acad. Sci. 110, 19507-19512. doi:10.1073/PNAS. 1318431110/-/DCSUPPLEMENTAL

Ji, Y., Dai, F., and Zhou, B. (2018). Designing Salicylaldehyde Isonicotinoyl Hydrazones as $\mathrm{Cu}(\mathrm{II})$ Ionophores with Tunable Chelation and Release of Copper for Hitting Redox Achilles Heel of Cancer Cells. Free Radic. Biol. Med. 129, 215-226. doi:10.1016/j.freeradbiomed.2018.09.017

Jiang, H., Taggart, J. E., Zhang, X., Benbrook, D. M., Lind, S. E., and Ding, W.-Q. (2011). Nitroxoline (8-Hydroxy-5-Nitroquinoline) Is More a Potent Anticancer Agent Than Clioquinol (5-Chloro-7-Iodo-8-Quinoline). Cancer Lett. 312, 11-17. doi:10.1016/J.CANLET.2011.06.032

Kang, X., Cai, Y., Wang, Q., Wang, C., Chen, W., Yang, W., et al. (2021). Nearinfrared Light Triggered Activation of Pro-drug Combination Cancer Therapy and Induction of Immunogenic Cell Death. Int. J. Pharmaceutics 607, 120972. doi:10.1016/J.IJPHARM.2021.120972

Kannappan, V., Ali, M., Small, B., Rajendran, G., Elzhenni, S., Taj, H., et al. (2021). Recent Advances in Repurposing Disulfiram and Disulfiram Derivatives as Copper-dependent Anticancer Agents. Front. Mol. Biosci. 8, 854. doi:10.3389/ FMOLB.2021.741316/BIBTEX

Lelièvre, P., Sancey, L., Coll, J.-L., Deniaud, A., and Busser, B. (2020). The Multifaceted Roles of Copper in Cancer: A Trace Metal Element with Dysregulated Metabolism, but Also a Target or a Bullet for Therapy. Cancers 12, 3594. doi:10.3390/cancers 12123594

Li, H., Wang, J., Wu, C., Wang, L., Chen, Z.-S., and Cui, W. (2020a). The Combination of Disulfiram and Copper for Cancer Treatment. Drug Discov. Today 25, 1099-1108. doi:10.1016/j.drudis.2020.04.003

Li, Y., Chen, F., Chen, J., Chan, S., He, Y., Liu, W., et al. (2020b). Disulfiram/Copper Induces Antitumor Activity against Both Nasopharyngeal Cancer Cells and Cancer-Associated Fibroblasts through ROS/MAPK and Ferroptosis Pathways. Cancers 202012, 138. Page 138 12. doi:10.3390/CANCERS12010138

Li, Y. (2020). Copper Homeostasis: Emerging Target for Cancer Treatment. IUBMB Life 72, 1900-1908. doi:10.1002/iub.2341

Li, Y., Zhao, P., Gong, T., Wang, H., Jiang, X., Cheng, H., et al. (2020c). Redox Dyshomeostasis Strategy for Hypoxic Tumor Therapy Based on DNAzymeLoaded Electrophilic ZIFs. Angew. Chem. Int. Ed. 59, 22537-22543. doi:10. 1002/anie.202003653

Liu, X., Wang, L., Cui, W., Yuan, X., Lin, L., Cao, Q., et al. (2016). Targeting ALDH1A1 by Disulfiram/copper Complex Inhibits Non-small Cell Lung Cancer Recurrence Driven by ALDH-Positive Cancer Stem Cells. Oncotarget 7, 58516-58530. doi:10.18632/ONCOTARGET.11305 
Ma, J., Wang, Q., Yang, X., Hao, W., Huang, Z., Zhang, J., et al. (2016). Glycosylated Platinum(iv) Prodrugs Demonstrated Significant Therapeutic Efficacy in Cancer Cells and Minimized Side-Effects. Dalton Trans. 45, 11830-11838. doi:10.1039/C6DT02207C

Mao, X., and Schimmer, A. (2008). The Toxicology of Clioquinol次. Toxicol. Lett. 182, 1-6. doi:10.1016/J.TOXLET.2008.08.015

Maslah, H., Skarbek, C., Pethe, S., and Labruère, R. (2020). Anticancer boron-containing Prodrugs Responsive to Oxidative Stress from the Tumor Microenvironment. Eur. J. Med. Chem. 207, 112670. doi:10.1016/J.EJMECH.2020.112670

McMahon, A., Chen, W., and Li, F. (2020). Old Wine in New Bottles: Advanced Drug Delivery Systems for Disulfiram-Based Cancer Therapy. J. Controlled Release 319, 352-359. doi:10.1016/J.JCONREL.2020.01.001

Michniewicz, F., Saletta, F., Rouaen, J. R. C., Hewavisenti, R. V., Mercatelli, D., Cirillo, G., et al. (2021). Copper: An Intracellular Achilles' Heel Allowing the Targeting of Epigenetics, Kinase Pathways, and Cell Metabolism in Cancer Therapeutics. ChemMedChem 16, 2315-2329. doi:10.1002/cmdc.202100172

Monk, B. J., Kauderer, J. T., Moxley, K. M., Bonebrake, A. J., Dewdney, S. B., Secord, A. A., et al. (2018). A Phase II Evaluation of Elesclomol Sodium and Weekly Paclitaxel in the Treatment of Recurrent or Persistent Platinum-Resistant Ovarian, Fallopian Tube or Primary Peritoneal Cancer: An NRG Oncology/gynecologic Oncology Group Study. Gynecol. Oncol. 151, 422-427. doi:10.1016/J.YGYNO.2018.10.001

Moradi, A., Srinivasan, S., Clements, J., and Batra, J. (2019). Beyond the Biomarker Role: Prostate-specific Antigen (PSA) in the Prostate Cancer Microenvironment. Cancer Metastasis Rev. 38, 333-346. doi:10.1007/s10555019-09815-3

Nagai, M., Vo, N. H., Shin Ogawa, L., Chimmanamada, D., Inoue, T., Chu, J., et al. (2012). The Oncology Drug Elesclomol Selectively Transports Copper to the Mitochondria to Induce Oxidative Stress in Cancer Cells. Free Radic. Biol. Med. 52, 2142-2150. doi:10.1016/J. FREERADBIOMED.2012.03.017

Nogueira, V., and Hay, N. (2013). Molecular Pathways: Reactive Oxygen Species Homeostasis in Cancer Cells and Implications for Cancer Therapy. Clin. Cancer Res. 19, 4309-4314. doi:10.1158/1078-0432.CCR-12-1424

O’Day, S., Gonzalez, R., Lawson, D., Weber, R., Hutchins, L., Anderson, C., et al. (2009). Phase II, Randomized, Controlled, Double-Blinded Trial of Weekly Elesclomol Plus Paclitaxel versus Paclitaxel Alone for Stage IV Metastatic Melanoma. Jco 27, 5452-5458. doi:10.1200/JCO.2008.17.1579

Oliveri, V. (2020). Biomedical Applications of Copper Ionophores. Coord. Chem. Rev. 422, 213474. doi:10.1016/J.CCR.2020.213474

Oliveri, V. (2015). New Glycoconjugates for the Treatment of Diseases Related to Metal Dyshomeostasis. ChemistryOpen 4, 792-795. doi:10.1002/open.201500155

Oliveri, V., and Vecchio, G. (2016). Prochelator Strategies for Site-Selective Activation of Metal Chelators. J. Inorg. Biochem. 162, 31-43. doi:10.1016/j. jinorgbio.2016.05.012

Pan, Q., Zhang, B., Peng, X., Wan, S., Luo, K., Gao, W., et al. (2019). A Dithiocarbamate-Based H2O2-Responsive Prodrug for Combinational Chemotherapy and Oxidative Stress Amplification Therapy. Chem. Commun. 55, 13896-13899. doi:10.1039/C9CC05438C

Park, Y. M., Go, Y. Y., Shin, S. H., Cho, J.-G., Woo, J.-S., and Song, J.-J. (2018). Anti-cancer Effects of Disulfiram in Head and Neck Squamous Cell Carcinoma via Autophagic Cell Death. PLoS One 13, e0203069. doi:10.1371/JOURNAL. PONE.0203069

Patra, M., Awuah, S. G., and Lippard, S. J. (2016a). Chemical Approach to Positional Isomers of Glucose-Platinum Conjugates Reveals Specific Cancer Targeting through Glucose-Transporter-Mediated Uptake In Vitro and In Vivo. J. Am. Chem. Soc. 138, 12541-12551. doi:10.1021/JACS.6B06937

Patra, M., Johnstone, T. C., Suntharalingam, K., and Lippard, S. J. (2016b). A Potent Glucose-Platinum Conjugate Exploits Glucose Transporters and Preferentially Accumulates in Cancer Cells. Angew. Chem. 128, 2596-2600. doi:10.1002/ANGE.201510551

Pavithra, V., Sathisha, T. G., Kasturi, K., Siva Mallika, D., Jeevan Amos, S., and Ragunatha, S. (2015). Serum Levels of Metal Ions in Female Patients with Breast Cancer. Jcdr 9, BC25-BC27. doi:10.7860/JCDR/2015/11627.5476

Raza, M. H., Siraj, S., Arshad, A., Waheed, U., Aldakheel, F., Alduraywish, S., et al. (2017). ROS-modulated Therapeutic Approaches in Cancer Treatment. J. Cancer Res. Clin. Oncol. 143, 1789-1809. doi:10.1007/ s00432-017-2464-9
Ruiz, L. M., Libedinsky, A., and Elorza, A. A. (2021). Role of Copper on Mitochondrial Function and Metabolism. Front. Mol. Biosci. 8, 691. doi:10. 3389/FMOLB.2021.711227/BIBTEX

Safi, R., Nelson, E. R., Chitneni, S. K., Franz, K. J., George, D. J., Zalutsky, M. R., et al. (2014). Copper Signaling axis as a Target for Prostate Cancer Therapeutics. Cancer Res. 74, 5819-5831. doi:10.1158/0008-5472.CAN-13-3527

Saleh, S. A. K., Adly, H. M., Abdelkhaliq, A. A., and Nassir, A. M. (2020). Serum Levels of Selenium, Zinc, Copper, Manganese, and Iron in Prostate Cancer Patients. Curr. Urol. 14, 44-49. doi:10.1159/000499261

Serra, R., Zhao, T., Huq, S., Gorelick, N. L., Casaos, J., Cecia, A., et al. (2021). Disulfiram and Copper Combination Therapy Targets NPL4, Cancer Stem Cells and Extends Survival in a Medulloblastoma Model. PLoS One 16, e0251957. doi:10.1371/JOURNAL.PONE.0251957

Shanbhag, V. C., Gudekar, N., Jasmer, K., Papageorgiou, C., Singh, K., and Petris, M. J. (2021). Copper Metabolism as a Unique Vulnerability in Cancer. Biochim. Biophys. Acta (Bba) - Mol. Cel Res. 1868, 118893. doi:10.1016/j.bbamcr.2020.118893

Shao, S., Si, J., and Shen, Y. (2019). Copper as the Target for Anticancer Nanomedicine. Adv. Therap. 2, 1800147. doi:10.1002/ADTP.201800147

Sharma, K., Mittal, D. K., Kesarwani, R. C., Kamboj, V. P., and Chowdhery (1994). Diagnostic and Prognostic Significance of Serum and Tissue Trace Elements in Breast Malignancy. Indian J. Med. Sci. 48, 227-232.

Skrott, Z., Mistrik, M., Andersen, K. K., Friis, S., Majera, D., Gursky, J., et al. (20172017). Alcohol-abuse Drug Disulfiram Targets Cancer via P97 Segregase Adaptor NPL4. Nature 552, 194-199. doi:10.1038/nature25016

Steinbrueck, A., Sedgwick, A. C., Brewster, J. T., Yan, K.-C., Shang, Y., Knoll, D. M., et al. (2020). Transition Metal Chelators, Pro-chelators, and Ionophores as Small Molecule Cancer Chemotherapeutic Agents. Chem. Soc. Rev. 49, 3726-3747. doi:10.1039/c9cs00373h

Stepien, M., Jenab, M., Freisling, H., Becker, N.-P., Czuban, M., Tjønneland, A., et al. (2017). Pre-diagnostic Copper and Zinc Biomarkers and Colorectal Cancer Risk in the European Prospective Investigation into Cancer and Nutrition Cohort. Carcinogenesis 38, 699-707. doi:10.1093/carcin/bgx051

Su, T. A., Shihadih, D. S., Cao, W., Detomasi, T. C., Heffern, M. C., Jia, S., et al. (2018). A Modular Ionophore Platform for Liver-Directed Copper Supplementation in Cells and Animals. J. Am. Chem. Soc. 140, 13764-13774. doi:10.1021/jacs.8b08014

Summers, K. L., Dolgova, N. V., Gagnon, K. B., Sopasis, G. J., James, A. K., Lai, B., et al. (2020). PBT2 Acts through a Different Mechanism of Action Than Other 8-hydroxyquinolines: An X-ray Fluorescence Imaging Study. Metallomics 12, 1979-1994. doi:10.1039/d0mt00222d

Sun, T., Yang, W., Toprani, S. M., Guo, W., He, L., Deleo, A. B., et al. (2020). Induction of Immunogenic Cell Death in Radiation-Resistant Breast Cancer Stem Cells by Repurposing Anti-alcoholism Drug Disulfiram. Cell Commun. Signal. 18, 36-14. doi:10.1186/S12964-019-0507-3/FIGURES/5

Szablewski, L. (2013). Expression of Glucose Transporters in Cancers. Biochim. Biophys. Acta (Bba) - Rev. Cancer 1835, 164-169. doi:10.1016/J.BBCAN.2012.12.004

Tai, S., Sun, Y., Squires, J. M., Zhang, H., Oh, W. K., Liang, C.-Z., et al. (2011). PC3 Is a Cell Line Characteristic of Prostatic Small Cell Carcinoma. Prostate 71, 1668-1679. doi:10.1002/pros.21383

Tang, Z., Liu, Y., He, M., and Bu, W. (2019). Chemodynamic Therapy: Tumour Microenvironment-Mediated Fenton and Fenton-like Reactions. Angew. Chem. 131, 958-968. doi:10.1002/ange.201805664

Trachootham, D., Alexandre, J., and Huang, P. (2009). Targeting Cancer Cells by ROS-Mediated Mechanisms: A Radical Therapeutic Approach? Nat. Rev. Drug Discov. 8, 579-591. doi:10.1038/nrd2803

Tsvetkov, P., Detappe, A., Cai, K., Keys, H. R., Brune, Z., Ying, W., et al. (2019). Mitochondrial Metabolism Promotes Adaptation to Proteotoxic Stress. Nat. Chem. Biol. 15, 681-689. doi:10.1038/s41589-019-0291-9

Vella, V., Malaguarnera, R., Lappano, R., Maggiolini, M., and Belfiore, A. (2017). Recent Views of Heavy Metals as Possible Risk Factors and Potential Preventive and Therapeutic Agents in Prostate Cancer. Mol. Cell Endocrinol. 457, 57-72. doi:10.1016/J.MCE.2016.10.020

Walther, R., Rautio, J., and Zelikin, A. N. (2017). Prodrugs in Medicinal Chemistry and Enzyme Prodrug Therapies. Adv. Drug Deliv. Rev. 118, 65-77. doi:10.1016/ J.ADDR.2017.06.013

Wang, D., Huang, J., Wang, X., Yu, Y., Zhang, H., Chen, Y., et al. (2013). The Eradication of Breast Cancer Cells and Stem Cells by 8-Hydroxyquinoline-Loaded Hyaluronan Modified Mesoporous Silica Nanoparticle-Supported Lipid Bilayers Containing Docetaxel. Biomaterials 34, 7662-7673. doi:10.1016/J.BIOMATERIALS.2013.06.042 
Wang, X., Zhong, X., Liu, Z., and Cheng, L. (2020a). Recent Progress of Chemodynamic Therapy-Induced Combination Cancer Therapy. Nano Today 35, 100946. doi:10.1016/j.nantod.2020.100946

Wangpaichitr, M., Wu, C., You, M., Maher, J., Dinh, V., Feun, L., et al. (2009). $\mathrm{N}^{\prime}$ 1, N'3-Dimethyl-N'1,N'3-bis(phenylcarbonothioyl) Propanedihydrazide (Elesclomol) Selectively Kills Cisplatin Resistant Lung Cancer Cells through Reactive Oxygen Species (ROS). Cancers 1, 23-38. doi:10.3390/cancers1010023

Weerasuriya, D. R. K., Wijesinghe, W. P. S. L., and Rajapakse, R. M. G. (2017). Encapsulation of Anticancer Drug Copper Bis(8-Hydroxyquinoline) in Hydroxyapatite for $\mathrm{pH}$-Sensitive Targeted Delivery and Slow Release. Mater. Sci. Eng. C 71, 206-213. doi:10.1016/J.MSEC.2016.10.010

Wehbe, M., Malhotra, A. K., Anantha, M., Lo, C., Dragowska, W. H., Dos Santos, N., et al. (2018). Development of a Copper-Clioquinol Formulation Suitable for Intravenous Use. Drug Deliv. Transl. Res. 8, 239-251. doi:10.1007/s13346-017-0455-7

Wu, W., Yu, L., Jiang, Q., Huo, M., Lin, H., Wang, L., et al. (2019). Enhanced Tumor-specific Disulfiram Chemotherapy by In Situ Cu2+ Chelation-Initiated Nontoxicity-To-Toxicity Transition. J. Am. Chem. Soc. 141, 11531-11539. doi:10.1021/jacs.9b03503

Xu, B., Wang, S., Li, R., Chen, K., He, L., Deng, M., et al. (2017). Disulfiram/copper Selectively Eradicates AML Leukemia Stem Cells In Vitro and In Vivo by Simultaneous Induction of ROS-JNK and Inhibition of NF- $\mathrm{BB}$ and Nrf2. Cell Death Dis 8, e2797. doi:10.1038/cddis.2017.176

Xu, X., Xu, J., Zhao, C., Hou, X., Li, M., Wang, L., et al. (2019). Antitumor Effects of Disulfiram/copper Complex in the Poorly-Differentiated Nasopharyngeal Carcinoma Cells via Activating ClC-3 Chloride Channel. Biomed. Pharmacother. 120, 109529. doi:10.1016/J.BIOPHA.2019.109529

Yip, N. C., Fombon, I. S., Liu, P., Brown, S., Kannappan, V., Armesilla, A. L., et al. (2011). Disulfiram Modulated ROS-MAPK and NFkB Pathways and Targeted Breast Cancer Cells with Cancer Stem Cell-like Properties. Br. J. Cancer 104, 1564-1574. doi:10.1038/bjc.2011.126
Yu, H., Zhou, Y., Lind, S. E., and Ding, W.-Q. (2009). Clioquinol Targets Zinc to Lysosomes in Human Cancer Cells. Biochem. J. 417, 133-139. doi:10.1042/ BJ20081421

Zhang, J., Duan, D., Xu, J., and Fang, J. (2018). Redox-Dependent Copper Carrier Promotes Cellular Copper Uptake and Oxidative Stress-Mediated Apoptosis of Cancer Cells. ACS Appl. Mater. Inter. 10, 33010-33021. doi:10.1021/acsami. 8 b11061

Zhang, X., and Yang, Q. (2018). Association between Serum Copper Levels and Lung Cancer Risk: A Meta-Analysis. J. Int. Med. Res. 46, 4863-4873. doi:10. $1177 / 0300060518798507$

Conflict of Interest: The author declares that the research was conducted in the absence of any commercial or financial relationships that could be construed as a potential conflict of interest.

The handling editor and reviewers QD and XC declared their involvement as coeditors in the Research Topic, and confirm the absence of any other collaboration.

Publisher's Note: All claims expressed in this article are solely those of the authors and do not necessarily represent those of their affiliated organizations, or those of the publisher, the editors and the reviewers. Any product that may be evaluated in this article, or claim that may be made by its manufacturer, is not guaranteed or endorsed by the publisher.

Copyright (C) 2022 Oliveri. This is an open-access article distributed under the terms of the Creative Commons Attribution License (CC BY). The use, distribution or reproduction in other forums is permitted, provided the original author(s) and the copyright owner(s) are credited and that the original publication in this journal is cited, in accordance with accepted academic practice. No use, distribution or reproduction is permitted which does not comply with these terms. 